\title{
BIODIESEL: VISÃO CRÍTICA DO STATUS ATUAL E PERSPECTIVAS NA ACADEMIA E NA INDÚSTRIA
}

\author{
Miguel J. Dabdoub* e João L. Bronzel \\ Departamento de Química, Faculdade de Filosofia, Ciências e Letras de Ribeirão Preto, Universidade de São Paulo, Av. Bandeirantes, 3900 , \\ 14040-901 Ribeirão Preto - SP, Brasil \\ Márcia A. Rampin \\ LADETEL - Laboratório de Desenvolvimento de Tecnologias Limpas, BiodieselBrasil, Rua Sete, 1410, 14850-000 Pradópolis - SP, Brasil
}

Recebido em 27/2/09; aceito em 31/3/09; publicado na web em 7/4/09

\begin{abstract}
BIODIESEL: A CRITICAL OVERVIEW ON THE CURRENT STATUS AND PERSPECTIVES AT THE ACADEMY AND INDUSTRY. This article presents a bibliographic review of research carried out on different alternative processes for biodiesel production. The supercritical and subcritical (non catalytic) reaction conditions, the use of solid basic, solid acid and other heterogeneous catalysts, including the use of immobilized enzymes and whole-cell catalysts are also critically compared with the traditional homogeneous alkaline or acid catalysts that are common on industrial applications. Advantages and limitations of all these processes for the transference from the laboratory to the industry are discussed. A correlation of the chemical composition with the quality parameters of the produced biodiesel is done with aim to stablish adequate procedures for the right selection of the rawmaterial. Castor bean oil is used as an example of inappropriate oil in order to produce a B100 that fulfill all the international physicochemical quality standards. In this article are presented research results to adequate the values of viscosity, density and iodine number of the castor and soybean biodiesel to the international standard limits by means blending these both biodiesels at the right ratio.
\end{abstract}

Keywords: transesterification; biodiesel; catalysts.

\section{INTRODUÇÃO}

Aumento da demanda mundial por combustíveis líquidos, aquecimento global, segurança energética, vontade política por desenvolvimento nos campos agrícola, social e também energético são pontos que abrem novas áreas de interesse e oportunidades para pesquisas e desenvolvimento na Academia e na Indústria, pois são as forças motoras responsáveis pelo renovado interesse na produção de biocombustíveis.

Um dos grandes destaques da atualidade na área de biocombustíveis é o interesse pelo uso de recursos naturais baseados em materiais lignocelulósicos ${ }^{1-3}$ para a produção de etanol ou por fontes produtoras de lipídeos usados para a produção de biodiesel.

Biodiesel é o nome dado a ésteres alquílicos de ácidos graxos desde que atendam certos parâmetros de qualidade. ${ }^{4-8}$ Além de esses ésteres serem derivados de fontes biológicas como plantas e animais, atuam como combustível substituto ao diesel de petróleo, com desempenho muito próximo, não exigindo modificações nos motores. Tradicionalmente o biodiesel é produzido através das reações de transesterificação de triglicerídeos, usando geralmente catalisadores alcalinos, ${ }^{9}$ ou da esterificação de ácidos graxos livres, sendo que neste último caso, os ácidos graxos livres (AGLs) são submetidos à reação direta com um álcool de 4 carbonos ou menos, na presença de catalisadores ácidos. ${ }^{10-12}$ Mais recentemente o uso de diversos catalisadores heterogêneos tem sido descrito na literatura. ${ }^{13}$

Transesterificação é o processo de transformação de um éster carboxílico em outro, através da troca do grupo $\mathrm{RO}^{-}$presente no éster original, por outro grupo semelhante proveniente de um álcool na presença de um catalisador ou não (condições supercríticas), para dar origem à glicerina e a mono-alquil ésteres (biodiesel).

$\mathrm{Na}$ Europa as especificações físico-químicas de qualidade para o biodiesel estão agrupadas na norma EN 14214, ${ }^{6}$ nos Estados Unidos estas são regulamentadas pela norma ASTM $6751 \mathrm{D},{ }^{4,5}$ enquanto no

\footnotetext{
*e-mail:migjodab@usp.br
}

Brasil o mesmo é feito através da resolução ANP 07/2008. ${ }^{8}$

O presente artigo pretende fazer uma análise crítica do status atual e das perspectivas, tanto para a academia quanto para a indústria, com base no que já foi publicado ou patenteado e nas aplicações atuais no âmbito industrial para a produção de biodiesel, incluindo resultados e opiniões dos autores de forma contextualizada. O mesmo não tem a intenção de ser uma revisão completa e exaustiva da literatura, mas sim um artigo de atualização adicional às revisões previamente realizadas até o ano de 2007 sobre catálise homogênea alcalina, ${ }^{9}$ ácida, ${ }^{10-12}$ heterogênea química, ${ }^{13}$ heterogênea enzimática ${ }^{14}$ e sobre o uso da guanidina..$^{15}$ Além disso, este artigo descreve a importância da identificação de matérias-primas adequadas, através da relação direta entre a composição química dos óleos ou gorduras e as características físicas e químicas do biodiesel que poderia ser obtido pela utilização das mesmas.

\section{HISTÓRICO}

Data de 31 de agosto de 1937, o depósito realizado pelo pesquisador belga Charles George Chavanne, da patente "Procédé de transformation d'huiles végétales em vue de leur utilisation comme carburants" visando a transformação de um óleo vegetal em ésteres metílicos e etílicos de ácidos graxos de cadeia longa, descrevendo claramente na reivindicação $\mathrm{n}^{\circ} 15$, a idéia da utilização dos mesmos como combustível para motores de combustão interna. ${ }^{16}$ Nessa patente ${ }^{16}$ e em outro artigo posterior do mesmo autor ${ }^{17}$ foi descrita a transesterificação do óleo de palma africana (dendê) com metanol ou etanol na presença de ácido sulfúrico como catalisador.

Estes trabalhos ${ }^{16,17}$ são um marco na história dos biocombustíveis líquidos e, em particular, na do biodiesel, porém, têm sido sistematicamente esquecidos, quando não omitidos, na literatura recente. Esse combustível, hoje poderia ser chamado de "óleo de Chavanne" em homenagem ao autor da brilhante idéia que fez possível a rodagem do primeiro ônibus "movido a biodiesel" já em 1938, na linha comercial de passageiros entre as cidades de Louvain e Bruxelas, na Bélgica, ${ }^{17}$ 
mas que, no entanto, passaria a ser chamado de biodiesel, apenas a partir de artigo publicado em 1988 por Wang. ${ }^{18}$

O desenvolvimento da reação de transesterificação de óleos vegetais com um álcool como o metanol ou etanol, sob catálise alcalina, ${ }^{19-24}$ foi registrado em vários artigos ${ }^{19,20}$ e patentes ${ }^{21-24}$ nas décadas de 40 e 50 . Apesar dos estudos de Chavanne ${ }^{16,17}$ citarem o uso desses ésteres como combustível, as referidas patentes ${ }^{21-24}$ destacam os processos inventados, com outras finalidades como, por exemplo, para o uso da glicerina.

A produção de "bio-gasolina" e "bio-querosene" a partir de óleos vegetais, como o de tungue e algodão, foi realizada ${ }^{25-27}$ através da técnica de craqueamento térmico ou catalítico, sendo um procedimento completamente diferente da reação de transesterificação. A partir de então, uma série de inovações tem sido descritas em artigos e patentes com o objetivo de melhorar os processos de produção e de refino ou, ainda, de oferecer métodos alternativos à produção desses ésteres.

No Brasil, a primeira patente requerida de um processo de transesterificação foi descrita em 1980 através do documento "Processo de produção de combustíveis a partir de frutos ou sementes de oleaginosas" PI- 8007957. ${ }^{28} \mathrm{O}$ uso de hidróxido de sódio (ou potássio) como catalisador alcalino e de ácidos, como o sulfúrico ou o clorídrico, foi descrito com o objetivo de produzir um combustível, de maneira semelhante à proposta feita por Chavanne 43 anos antes. Esse trabalho ${ }^{28}$ descreve a possibilidade de separação dos ésteres em frações leves e frações pesadas, através da destilação sob vácuo, do biodiesel obtido a partir das amêndoas de babaçú. A fração de peso molecular mais baixo (fração leve) serviria como substituto do querosene de petróleo (bioquerosene) e a fração mais pesada como sucedâneo do óleo diesel de petróleo (biodiesel). Na mesma patente ainda é descrito o uso de micro-ondas ou de ultrassom para tornar mais eficiente a extração do óleo vegetal.

Posteriormente, outros autores têm empregado essas técnicas para acelerar a reação de transesterificação. Na realidade, seu uso tem contribuição desprezível na aceleração do processo de produção do biodiesel como um todo, já que a reação de transesterificação está longe de ser a etapa limitante do processo, principalmente quando se considera o tempo (intervalo entre input de matéria-prima e output de produto acabado) de produção desse combustível em escala industrial.

$\mathrm{Na}$ atualidade, o potencial do uso do biodiesel como fonte energética "Nova e Renovável" é um dos assuntos mais discutidos no âmbito industrial e acadêmico, embora esse "velho" combustível já seja utilizado em um grande número de países mesmo enfrentando sérias dificuldades para competir com o diesel de petróleo, o que tem forçado alguns países a estabelecer programas de subsídio ou de uso obrigatório nas misturas com diesel como é o caso do Brasil.

\section{PROCESSO INDUSTRIAL, CATÁLISE ALCALINA E CATÁLISE ÁCIDA}

A grande maioria dos processos de produção industrial do biodiesel ao redor do mundo emprega atualmente o metóxido de sódio como catalisador, embora isto exija o uso de óleos neutros, com baixo teor de ácidos graxos livres e com baixo teor de água. ${ }^{29} \mathrm{O}$ metóxido de sódio é obtido comercialmente em soluções de diferentes concentrações, pronto para uso, livre de água, o que aumenta a sua eficiência e reduz drasticamente a formação de sabões e, por consequência, de emulsões indesejáveis, diferentemente do que ocorre no caso da preparação in situ do alcóoxido, empregando a soda cáustica ou a potassa cáustica como catalisadores. ${ }^{9,29}$

Estes dois últimos catalisadores podem ser considerados ultrapassados, uma vez que mesmo quando se utilizam óleos vegetais refinados, com baixo teor de ácidos graxos livres e baixo teor de água, pequenas quantidades de sabões ainda são formadas, promovendo o arraste de quantidades variáveis de ésteres junto com a fase glicerinosa, reduzindo assim o rendimento dos ésteres na fase leve e gerando uma glicerina contendo mais contaminantes.

Esse inconveniente pode causar dificuldades de separação das fases, exigindo maiores cuidados durante o refino dos ésteres, se realizado por lavagem úmida (uso de água) e resultando no incremento de operações unitárias necessárias para "fechar o ciclo produtivo", o qual é um requisito fundamental para alcançar a competitividade do processo industrial.

Também, durante o refino dessa glicerina, os contaminantes deverão ser separados, exigindo o uso de mais equipamentos, mais reagentes químicos e mais operações unitárias, aumentando o consumo energético da unidade produtiva.

A nossa experiência tem mostrado que a fase glicerinosa separada da fase que contém os ésteres, ao ser tratada com ácidos, como o sulfúrico, clorídrico, fosfórico, ou por outros métodos, como o uso de resinas de troca iônica (ácidas), resulta na separação de duas novas fases, cujos volumes podem ser variáveis dependendo da qualidade do óleo vegetal (teor de AGLs e conteúdo inicial de água), bem como do volume de álcool empregado na reação de transesterificação.

Quando se empregam óleos refinados, como o óleo de soja comercial, essas fases separam em proporções volumétricas equivalentes (1:1) sendo que após a "acidificação", a fase inferior conterá glicerina, álcool, água e sais derivados do catalisador e do ácido mineral empregados. Uma segunda fase mais leve (superior) é obtida, contendo aproximadamente $40 \%$ do volume em ácidos graxos livres e $60 \%$ de ésteres alquílicos de ácidos graxos. Para que esta última mistura seja aproveitada é necessário submetê-la à posterior esterificação com o álcool sob catálise ácida utilizando, por exemplo, o ácido sulfúrico. . $^{5,10-12,17,30,31}$

Para uma aplicação eficiente deste método em escala industrial, ainda é necessário implementar a recuperação de todas as substâncias químicas envolvidas, permitindo o completo reaproveitamento e quando possível a reutilização destas, no mesmo processo produtivo. Esse fato seria aplicável ao álcool que é empregado em excesso, à água usada durante o refino (lavagem dos ésteres), e à derivatização do catalisador empregado, permitindo transformar este último em algum produto químico reutilizável, evitando assim a formação de qualquer efluente contaminante líquido ou sólido. Da mesma forma, deve ser dado um destino adequado e com agregação de valor à glicerina gerada, caso contrário este subproduto pode comprometer a economicidade de qualquer processo de produção de biodiesel. No momento atual ainda não se conhecem aplicações em larga escala que permitam a absorção de toda a glicerina gerada nas usinas de biodiesel.

Assim, dois fatores operacionais e indispensáveis para a produção economicamente viável do biodiesel na indústria são: eficiência energética de todo o processo industrial, o que envolve a recuperação de energia através do emprego de trocadores de calor e economizadores que permitam o aproveitamento total ou parcial do calor excedente de uma operação unitária (por exemplo, a etapa da secagem do biodiesel) em outra operação unitária como no aquecimento, antes ou durante a reação, ou ainda na recuperação do álcool e; uso de matérias-primas com características físico-químicas adequadas, disponíveis em larga escala possibilitando a redução de custos, uma vez que na atualidade, o custo da matéria-prima é responsável por 70 a $88 \%$ do preço final do biodiesel. ${ }^{32,33}$

Uma das tentativas de aumentar a competitividade da produção envolve o uso de matérias-primas de baixo custo, as quais são consideradas de "baixa qualidade" devido ao alto (e variável) conteúdo de ácidos graxos livres (AGLs) como, por exemplo, óleos utilizados em processos de fritura, óleos vegetais brutos (não refinados), entre outros. Porém, esses materiais não são adequados ao processo de 
transesterificação alcalina, tornando quase obrigatória a purificação dos mesmos através dos processos de refino químico (neutralização com $\mathrm{NaOH}$, centrifugação/lavagem com água, centrifugação/secagem sob vácuo) ou refino físico (destilação dos ácidos graxos sob alto vácuo e alta temperatura). A aplicação do processo de refino, neste caso, requer alto investimento adicional em instalações industriais e agrega custo adicional à matéria-prima.

Alternativamente, esses óleos podem ser submetidos a processos que combinam a catálise ácida e alcalina, geralmente nessa ordem, ${ }^{34-36}$ mas também na ordem inversa ${ }^{37,38}$ permitindo a transformação completa de TGs e AGLs nos ésteres desejados.

Ocorre, porém, um incremento significativo no uso de catalisador, além do aumento de número de etapas e, também, a necessidade de reatores e equipamentos fabricados com materiais especiais e de elevado custo, devido ao uso de ácido sulfúrico, metano sulfônico, p-tolueno-sulfônico e outros, que têm a sua corrosividade usual ainda mais potencializada nas condições de alta temperatura empregadas, sem contar a geração de grandes quantidades de efluentes que precisam ser neutralizados. Esses fatos minimizam ou eliminam os ganhos pretendidos pelos autores com sua aplicação. ${ }^{34-38}$

Aqui podemos apontar uma grande oportunidade de pesquisa no âmbito acadêmico e industrial, que consiste no estabelecimento de novos processos químicos de pré-tratamento ou refino de matérias-primas com alto teor de AGLs, alternativos aos processos já descritos.

No geral os alcolatos metálicos como, por exemplo, o metilato de sódio $\left(\mathrm{NaOCH}_{3}\right)$ são os catalisadore $\mathrm{s}^{39,40}$ mais ativos e mais utilizados em escala industrial, pois além dos tempos de reação reduzidos, podem ser utilizados em baixas concentrações fornecendo altos rendimentos reacionais (> 99\%) sob condições reacionais moderadas. Considerando que com o uso deste catalisador a fase glicerinosa se separa facilmente da fase que contém os ésteres, o processo produtivo aplicado na indústria permite a realização de duas etapas reacionais de transesterificação, o que torna o processo ainda mais eficiente, graças ao equilíbrio reacional poder ser deslocado mais rapidamente. Na primeira etapa, 95 a $98 \%$ dos triglicerídeos são transformados em monoalquil ésteres, e a glicerina pode ser fisicamente removida (decantação ou centrifugação) do sistema. Subsequentemente, a fase que contém os ésteres e alguns intermediários ainda não reagidos, como mono e diglicerídeos, é submetida a uma segunda reação de transesterificação com quantidades menores de metanol e de metóxido de sódio (catalisador) do que aquelas usadas na primeira etapa, permitindo alcançar 99 a 100\% de transformação.

O processo em duas etapas empregando reatores adequados, razão molar metanol:óleo igual a 6:1 e temperatura entre 45 e $60{ }^{\circ} \mathrm{C}$ permite a execução de cada uma das etapas em tempos reacionais extremamente curtos, possibilitando a produção em regime contínuo, uma vez que o tempo de residência em cada um dos dois reatores é sempre inferior a $2 \mathrm{~min}$, diferentemente da produção em regime descontínuo (bateladas) onde no melhor dos casos o tempo da reação de transesterificação ocorrerá em torno de $30 \mathrm{~min},{ }^{41}$ embora existam alguns relatos de tempo de até $8 \mathrm{~h} .{ }^{41}$

Entretanto, neste processo continua sendo necessário o uso de lipídeos refinados, com baixos teores de ácidos graxos livres como também de alcoóis totalmente anidros, o que tem seu custo intrínseco, e que se reflete no custo da matéria-prima e, por consequência, do biodiesel produzido. ${ }^{42}$

Nenhum processo reacional sozinho permite obter diretamente os ésteres alquílicos de ácidos graxos nas especificações mínimas necessárias para ser usado como combustível e ser chamado de biodiesel, conforme as normas ASTM 6751, EN 14214, ANP 07/2008, sem a necessidade de se aplicar algumas etapas de purificação posteriores à transesterificação. ${ }^{43}$
Neste sentido, apesar de a maior parte da glicerina ser removida por decantação ou centrifugação (fase mais pesada), resíduos da mesma permanecem na fase mais leve que contêm os ésteres. $\mathrm{O}$ mesmo é válido para o álcool (metanol ou etanol) que, utilizado em excesso, tem parte arrastada pela fase glicerinosa, enquanto parte dele fica na fase leve que contêm os ésteres, o qual pode ser removido por evaporação ou por lavagem do biodiesel com água. Além disso, outras etapas adicionais ou alternativas para a purificação do biodiesel são necessárias, como a neutralização, lavagem (que pode ser por via úmida ou via seca) e evaporação/secagem (para remoção da água ou resíduos de metanol em função do tipo de lavagem adotada), as quais consomem mais tempo de processo do que a reação propriamente dita e elevam ainda mais o custo da produção. Entretanto, estas etapas são indispensáveis para alcançar as especificações mínimas de qualidade, garantindo a remoção de resíduos de catalisador, glicerina livre residual, sabões e outros contaminantes do produto final.

$\mathrm{O}$ inconveniente que tem sido sistematicamente levantado na literatura e apontado como principal desvantagem do processo de catálise alcalina é a geração de grandes quantidades de efluentes aquosos alcalinos ${ }^{9,44,45}$ quando se utiliza a "lavagem por via úmida" para a remoção do catalisador dissolvido, de qualquer sabão que esteja presente, além da remoção completa do álcool e de qualquer tipo de material inorgânico. Este processo exige, consequentemente, a secagem final do produto.

Alternativamente ao uso da água pode ser realizada a "lavagem a seco" empregando adsorventes ou resinas de troca iônica que removam todas as impurezas. ${ }^{43,46,47}$ Estas resinas são comercializadas com as marcas Rohm and Haas (BD 10 DRY), Purolite (PD 206) ou Lanxess (Lewattit 15). Os adsorventes sólidos ${ }^{43,46,47}$ podem ser alumina, sílica, silicatos, incluindo o silicato de magnésio (Magnesol, comercializado pela Dallas Corporation) e outros.

Portanto, é importante destacar que, para se ter uma produção eficiente de biodiesel há uma grande necessidade por estabelecer desenhos de processo e parâmetros operacionais que permitam:

1- utilizar qualquer matéria-prima independente da sua origem (gorduras animais ou óleos de qualquer grão ou fruto) através da: 1.a- padronização da matéria-prima para empregar o catalisador escolhido de forma eficiente e satisfatória. Por exemplo, através do refino completo ou simplesmente pela neutralização e secagem dos lipídeos, quando for necessário utilizar catalisadores alcalinos como $\mathrm{NaOCH}_{3} ; 1$.b- opção pela catálise ácida homogênea ${ }^{48-50}$ ou sólidos ácidos como catalisadores heterogêneos ${ }^{51,52}$ caso a matéria-prima seja constituída essencialmente ou na sua maioria por ácidos graxos, independentemente da origem dos lipídeos. A forma mais comum de transformar AGLs em biodiesel por esterificação é usando ácido sulfúrico, ${ }^{9,10,16,17,48-50}$ p-tolueno sulfônico ou alquilbenzeno sulfônico ${ }^{41}$ como catalisador; 1.c- opção pela combinação da esterificação seguida da transesterificação ${ }^{34,36}$ ou até mesmo utilizando a sequência oposta destas reações, iniciando-se pela transesterificação e posterior esterificação, ${ }^{37,38}$ caso o conteúdo de ácidos graxos no óleo ou gordura estejam acima de $2 \%$. Alternativamente pode se optar pelo pré-tratamento do óleo, seja ele realizado por refino físico ou refino químico.

2- Evitar a formação de subprodutos ou a permanência de intermediários indesejados, como mono e diglicerídeos, no produto final.

3- Minimizar ou eliminar totalmente a produção de efluentes.

Um dos subprodutos mais problemáticos são os sabões, pois facilitam a formação de emulsões e promovem o arraste de ésteres para a fase glicerinosa. No caso da catálise alcalina com $\mathrm{NaOCH}_{3}$ isso pode ser quase que totalmente evitado através do uso de lipídeos isentos de água e/ou de ácidos graxos livres (ver item 1.a). Quando a matéria-prima é de baixa qualidade deve-se aplicar a situação mais adequada entre 1.a, 1.b e 1.c. 
Já no caso dos mono e diglicerídeos intermediários não haverá nenhum problema que relacione os altos teores, pois os procedimentos tradicionais alcalinos $\left(\mathrm{NaOCH}_{3}\right)$ ou ácidos, desde que os itens 1.a, 1.b e 1.c sejam adequadamente escolhidos em função da matéria-prima disponível e desde que a reação química seja corretamente executada, permitirão a conversão total a biodiesel.

No campo acadêmico ainda se persegue o desenvolvimento do catalisador ideal, mas para ter maior validade e aplicabilidade na indústria, esse catalisador deverá fazer parte de um processo ideal ou no mínimo "otimizado". Neste sentido, a utilização adequada do metóxido de sódio $\left(\mathrm{NaOCH}_{3}\right)$ em um processo otimizado, em ciclo fechado, ainda não foi superada em termos de viabilidade técnica, energética ou econômica pelo uso de nenhum outro catalisador ou processo, superando de longe o uso de hidróxidos alcalinos, o que justifica o uso cada vez menos frequente destes últimos na indústria.

Assim, o processo industrial de transesterificação otimizado, utilizando o $\mathrm{NaOCH}_{3}$ anidro, envolve:

transesterificação total e realizada sob regime contínuo;

reação e purificação resultando em níveis baixos de metanol, água, mono e diglicerídeos, além de glicerina livre atendendo às especificações físico-químicas de qualidade;

- transformação, das correntes glicerinosa e aquosa (da lavagem do biodiesel) em uma única (corrente) solução que depois de neutralizada é submetida à separação (recuperação e retificação) total do álcool para reuso no processo, seguido da destilação da água também para reutilização no processo de lavagem;

- separação e utilização dos ácidos graxos que possam ter se formado; concentração da glicerina;

filtração e purificação de sais (derivados do catalisador e do ácido usado na neutralização) para lhes dar um uso adequado;

- desenho do processo levando em consideração a eficiência energética, recuperando e reutilizando o calor de uma operação unitária em outra.

Embora acreditemos que o $\mathrm{NaOH}$ ou $\mathrm{KOH}$ não tenham grande futuro no médio e longo prazo, para uma produção industrialmente competitiva, em 2008, das publicações que envolvem a reação de transesterificação, mais de uma dúzia de artigos empregaram $\mathrm{NaOH}$ e/ou KOH como catalisadores. ${ }^{34,35,53-64}$ Porém, em termos de reação de transesterificação e purificação do biodiesel, esses artigos, científica e industrialmente falando, não trazem contribuição significativa que possa melhorar a economicidade da produção ou alavancar o crescimento do uso massivo do biodiesel na matriz energética brasileira ou de outros países.

Considerando que a reação com $\mathrm{NaOCH}_{3}$ em duas etapas pode levar apenas alguns minutos, o uso da $\mathrm{NaOH}$ ou $\mathrm{KOH}$, aliado à irradiação de micro-ondas, com o objetivo de reduzir o tempo reacional, ${ }^{53,54}$ não representa vantagem operacional nenhuma em relação ao uso de aquecimento convencional, que justifique o scale-up para o seu uso na indústria.

No caso da transesterificação do óleo de mamona empregando essas condições, os autores utilizaram alumina básica como suporte sólido $\left(\mathrm{Al}_{2} \mathrm{O}_{3} / 50 \% \mathrm{KOH}\right)$ e embora afirmem ${ }^{53}$ que esse catalisador pode ser reutilizado por vários ciclos, não dão detalhes do número preciso de ciclos e se ocorre ou não perda da atividade devido à solubilização do $\mathrm{KOH}$ no álcool empregado (lixiviação). Além disso, a proporção de catalisador é elevada. Foi utilizada uma relação de óleo:catalisador de 10:1 (ou 10\% de catalisador) o que equivale a 2,5 g de $\mathrm{KOH}$ por cada $50 \mathrm{~g}$ de óleo transesterificado ou ainda uma proporção de $5 \%$ do uso de $\mathrm{KOH}$, o que é uma séria desvantagem em relação ao uso convencional de $\mathrm{KOH} .{ }^{29} \mathrm{O}$ mesmo trabalho descreve a utilização de $\mathrm{H}_{2} \mathrm{SO}_{4} 50 \%$ adsorvido em sílica como catalisador na transesterificação assistida por micro-ondas, mas não aponta a solução aos problemas que seriam encontrados na aplicação desse método em larga escala como a corrosão causada aos reatores, necessidade do tratamento de efluentes ácidos gerados, e outros.

Azcan e Danisman ${ }^{54}$ relatam em outro artigo de 2008 a transesterificação do óleo de colza (canola) também empregando KOH e $\mathrm{NaOH}$ como catalisadores em reações assistidas por irradiação de micro-ondas. Estes autores usaram 0,5; 1,0 e 1,5\% de catalisador e determinaram que a proporção ideal é 1,0\%, uma vez que não houve ganhos significativos passando de 1,0 a 1,5\%. Esses resultados estão de acordo com dados anteriores da literatura que usaram micro-ondas e condições semelhantes, realizando a reação em 5 min e 1,3\% de $\mathrm{NaOH}$ para o óleo de colza, ${ }^{65} 4$ min para óleos de fritura ${ }^{66}$ e 7 min para o óleo de algodão. ${ }^{67}$

Outros óleos têm sido transesterificados com metanol usando $\mathrm{NaOH}^{55-60}$ ou KOH ${ }^{57,60,61}$ ou ainda submetidos inicialmente à esterificação com ácido sulfúrico devido ao alto conteúdo de AGLs, seguido de transesterificação com $\mathrm{NaOH}$ ou com $\mathrm{KOH}$ como catalisador. ${ }^{34,35,62-64}$ Entre esses óleos estão o de tucum,,$^{55} \mathrm{o}$ de peixe marinho bruto, ${ }^{56}$ colza (canola), ${ }^{57}$ girassol, ${ }^{58}$ palmiste,${ }^{59}$ karanja ${ }^{60}$ e gergelim. ${ }^{61}$ Esses mesmos catalisadores também têm sido usados após pré-tratamento (esterificação) com ácido sulfúrico e metanol dos óleos brutos que continham altos teores de AGLs, como é o caso dos óleos de pinhão manso (Jatropha curcas), ${ }^{62,63}$ semente de seringueira (rubber seed oil), ${ }^{34}$ tabaco (Nicotina tabacum L. ${ }^{35}$ e polanga. ${ }^{64}$

Estudos da cinética da reação de transesterificação do óleo de soja com metanol e butanol realizados por Freedman e colabores ${ }^{68}$ mostraram que rendimentos reacionais melhoram quando a reação é realizada a temperaturas próximas ao ponto de ebulição, particularmente no caso do metanol.

A etanólise de óleos vegetais tem sido estudada com menor frequência em relação à metanólise e o uso de $\mathrm{NaOH}$ ou $\mathrm{KOH}$ é apontado como sendo mais problemático na etanólise do que no caso da metanólise. As diferenças nos processos de obtenção de biodiesel etílico e metílico podem chegar a ser bastante significativas dependendo da qualidade da matéria-prima, do teor de ácidos graxos livres, do teor de água e, inclusive, das condições experimentais empregadas. A falta de compreensão desses fatores pode afetar a sua aplicação em escala industrial. Porém, resultados interessantes descritos por outros autores, ${ }^{69-72}$ têm ajudado a entender melhor a produção de biodiesel etílico com o uso desses catalisadores. Esses estudos mostram que mudanças nas temperaturas reacionais, por exemplo, exercem pequena influência na reação de etanólise de triglicerídeos derivados de soja ${ }^{69,70}$ girassol e sementes de Raphanus sativus ${ }^{71} \mathrm{e}$ óleo residual de frituras. ${ }^{72}$

\section{CONDIÇÕES SUPERCRÍTICAS E SUBCRÍTICAS}

Apoiados na constante discussão sobre as desvantagens do uso dos catalisadores homogêneos sejam eles alcalinos ou ácidos, Saka e Kusdiana ${ }^{73,74}$ desenvolveram um processo de transesterificação que não utiliza catalisador e é realizado com metanol sob condições supercríticas (temperatura e pressão em condições supercríticas). As vantagens reivindicadas por esses autores incluem o fato de que a reação não é sensível à presença de ácidos graxos livres, não ocorre formação de sabões ou emulsões, o tempo reacional é relativamente curto (ao redor de $4 \mathrm{~min}$ ) e a purificação do biodiesel é simplificada, pois não há necessidade de neutralização ou lavagem. Nesse trabalho, o óleo de canola foi convertido em biodiesel usando uma razão óleo: metanol de 1:42 a $350{ }^{\circ} \mathrm{C}$ e sob pressão de $30 \mathrm{MPa} .{ }^{74}$

As condições experimentais utilizadas para a síntese do biodiesel com metanol supercrítico são responsáveis pela grande desvantagem desse processo, pois é requerido um elevado teor de metanol, os equipamentos necessários são de elevadíssimo custo devido à alta pressão e temperatura empregadas, além do elevado consumo energético pelo 
qual não é viável para aplicação industrial. Em função disso, um dos grandes desafios é conseguir suavizar as condições reacionais deste processo não-catalítico.

Algumas tentativas descritas na literatura têm permitido amenizar a pressão, a temperatura e o excesso necessário do metanol utilizado. Embora esses resultados ainda não sejam drásticos ou altamente significativos. Esses trabalhos utilizaram dióxido de carbono ${ }^{75}$ ou hexano ${ }^{76}$ como cossolvente na produção do biodiesel de soja ou ainda óxido de cálcio como "correagente" para a obtenção de biodiesel de girassol. ${ }^{77}$ Contudo, deve ser levado em consideração que o óxido de cálcio como catalisador básico sólido pode ser envenenado pela presença de ácidos graxos livres, com os quais reage formando um composto inerte. ${ }^{78}$

Em trabalho publicado em 2008 por Yin et al. ${ }^{79}$ foram descritos resultados comparativos da transesterificação do óleo de soja com metanol em condições supercríticas e em condições subcríticas. Realizando a reação com uma relação metanol:óleo de 42:1 a uma temperatura de $350{ }^{\circ} \mathrm{C}$ e sob pressão de $20 \mathrm{Mpa}$ durante $10 \mathrm{~min}$ na ausência de catalisador, o rendimento do biodiesel atingiu 95\%, subindo para $98 \%$ após 60 min de reação.

Segundo os autores, o uso de $\mathrm{CO}_{2}$ ou de hexano como cossolvente possibilitou a diminuição da temperatura reacional para 300 ${ }^{\circ} \mathrm{C}$. Por outro lado, a adição de $0,1 \%$ em peso de $\mathrm{KOH}$ possibilitou a execução da reação em condições subcríticas $\left(160{ }^{\circ} \mathrm{C}\right)$ durante 30 min, ${ }^{79}$ sendo que com a razão metanol:óleo de $6: 1$ o rendimento foi de $38 \%$. Aumentando essa relação para 24:1 o tempo foi reduzido para 5 min e o rendimento da reação atingiu $100 \%$, à temperatura de 240 ${ }^{\circ} \mathrm{C}$. Porém, as temperaturas e pressões empregadas ainda são muito altas. Além disso, a "volta" ao uso do $\mathrm{KOH}$ como catalisador não representa vantagem nenhuma que justifique a aplicação deste tipo de procedimento em escala industrial, quando se comparam vantagens e desvantagens em relação ao processo clássico que utiliza metóxido de sódio anidro e razões metanol:óleo, não maiores que 6:1.

Hawash et al., ${ }^{80}$ em trabalho recente, descrevem os resultados da produção de biodiesel de Jatropha curcas (pinhão manso) pelo processo não-catalítico com metanol sob condições supercríticas. Esses autores obtiveram os ésteres desejados em $100 \%$ de rendimento após 4 min de reação e usando uma relação molar álcool:óleo de 43:1 a $593 \mathrm{~K}$ e 8:4 MPa.

Portanto, é clara a necessidade de amenizar ou minimizar os requerimentos energéticos da reação, assim como de diminuir as razões álcool:óleo para que os procedimentos em condições super ou subcríticas possam ganhar aplicabilidade e trazer para a realidade as "justificativas acadêmicas" de que são métodos superiores aos métodos químicos convencionais, pois requerem menos purificação dos produtos.

Caso contrário, as pesquisas continuarão sendo desenvolvidas nos mesmos parâmetros, modificando somente a origem ou tipo dos óleos empregados, sem contribuir para as soluções necessárias.

\section{CATÁLISE HETEROGÊNEA ÁCIDA E ALCALINA}

Embora o uso da catálise tradicional homogênea com $\mathrm{NaOCH}_{3}$ tenha já sido otimizada para a sua aplicação industrial, existe na literatura o consenso de que a recuperação do catalisador homogêneo é muito complicada, resultando em perda desse material, sendo, portanto, descrita como uma séria desvantagem. Devido a isso, o desenvolvimento de novos catalisadores para a produção de biodiesel é, na atualidade, uma área de pesquisa muito ativa e dinâmica, tanto na área acadêmica como industrial. ${ }^{81-85}$

Muita atenção tem sido focada em sistemas heterogêneos no intuito de aumentar a eficiência da produção, reduzir os custos do biodiesel e eliminar o que é descrito como as grandes desvantagens da catálise alcalina. O uso de catalisadores sólidos (heterogêneos) recebe destaque especial, pois a recuperação do catalisador é mais simples a partir da mistura sólido-líquido. Outra grande vantagem é que a catálise heterogênea elimina a possibilidade de formação de sabão, salvo algumas exceções como é o caso do uso do $\mathrm{CaO} .{ }^{86} \mathrm{Na}$ sequência será discutida a catálise heterogênea com o intuito de se entender melhor as vantagens, as limitações e o potencial de aplicação desses catalisadores para a produção de biodiesel em escala comercial.

Uma série de catalisadores ácidos e básicos sólidos com características de ação heterogênea foram intensivamente pesquisados, nos últimos anos, o que se reflete no número crescente de publicações e patentes na área. Na literatura podem ser encontrados diversos outros tipos de catalisadores heterogêneos que, em geral, podem ser classificados em três grandes grupos: catalisadores sólidos alcalinos, catalisadores sólidos ácidos e enzimas imobilizadas. ${ }^{9,14,87-89}$

Muitos catalisadores heterogêneos têm mostrado alta eficiência e atividade na reação de transesterificação e também na esterificação de ácidos graxos livres, porém sempre sob alta temperatura e pressão, além de longos tempos reacionais requeridos. Isso tem limitado muito a aplicação industrial dos mesmos, a despeito de simplificarem o processo de produção facilitando a separação do catalisador e as etapas de purificação. ${ }^{9,87-89}$

Até o presente só existe uma descrição da produção comercial de biodiesel por transesterificação baseada no emprego de um catalisador heterogêneo que tem sido comercializado pelo Instituo Francês do Petróleo (IFP) e pela empresa Axens. ${ }^{90,91} \mathrm{O}$ uso desse catalisador, que é um óxido de zinco e alumínio e que seria $100 \%$ insolúvel no meio reacional e, portanto, realmente heterogêneo, foi anunciado em 2004 e provavelmente pelo alto consumo energético (alta temperatura e alta pressão) do processo, assim como pela sua baixa atividade, não tem resultado em uma utilização expressiva no mercado internacional.

Outra descrição na literatura sobre o emprego, na indústria, de um catalisador heterogêneo envolve a reação de esterificação para a produção de biodiesel a partir dos ácidos graxos destilados de óleo de palma (dendê). Neste caso o álcool empregado foi o metanol e o catalisador à base de nióbio $\left(\mathrm{Nb}_{2} \mathrm{O}_{5}\right){ }^{92,93}$ Porém, os nossos trabalhos com a empresa produtora ${ }^{92}$ deste biodiesel e análises de materiais contidos nesse produto indicam que o catalisador é o ácido metanossulfônico.

Grandes esperanças são depositadas na aplicabilidade de catalisadores heterogêneos, porém para que eles sejam economicamente competitivos, é necessário que este catalisador seja muito eficiente a temperaturas abaixo de $120{ }^{\circ} \mathrm{C}$ e no máximo 2 a $3 \mathrm{~kg} / \mathrm{cm}^{2}$ de pressão. Ainda na busca pelo catalisador ideal podemos enumerar outras qualidades requeridas:

o catalisador deverá realizar de preferência a transesterificação de TGs, DGs, MGs e a esterificação de AGLs, simultaneamente, possibilitando o uso de qualquer matéria lipídica sem a necessidade de refino ou pré-tratamento;

o catalisador deve ser tolerante à presença de água e AGLs;

deve atuar em temperaturas moderadas e de preferência à pressão atmosférica;

o catalisador deverá ser $100 \%$ insolúvel no meio reacional, atuando de forma $100 \%$ heterogênea, para facilitar a sua remoção e a purificação, tanto da fase glicerinosa quanto do biodiesel;

o catalisador deverá ser reutilizável mantendo a sua atividade e possibilitando o seu reuso ou recuperação por reativação; apresentar alta eficiência e atividade;

- não deverá promover reações paralelas que resultem na formação de sabões ou outras substâncias, que não sejam os monoalquil ésteres e a glicerina.

- não ter a sua atividade catalítica diminuída para poder ser reutilizado; 
- de preferência ser produto de fácil obtenção comercial;

não apresentar barreiras econômicas intransponíveis;

deve promover reações rápidas permitindo sua utilização em regime contínuo.

Na tentativa de se atingir esses objetivos, inúmeros artigos científicos que apontam para o uso de catalisadores heterogêneos na reação de transesterificação têm sido publicados. Esses trabalhos descrevem o uso de resinas poliméricas de troca-iônica, ${ }^{94,95}$ membranas, ${ }^{96,97}$ complexos metálicos, ${ }^{83}$ metais ativos em suportes sólidos, ${ }^{84,85}$ óxidos metálicos, ${ }^{44,98-101}$ zeólitas, ${ }^{102,103}$ enzimas do tipo lipases. ${ }^{104,105}$

Dentre os catalisadores ácidos heterogêneos com potencial de substituição dos ácidos minerais e ácidos orgânicos homogêneos utilizados na obtenção de biodiesel por esterificação e transesterificação, podemos citar os óxidos de tungstênio, ${ }^{106-108}$ resinas Amberlyst ${ }^{\circledR} 15,{ }^{31,109,110}$ Lewattit GF $101,{ }^{109}$ Saccharideos sulfonados, ${ }^{51,111}$ Nafion ${ }^{\circledR}, 31,95,109,112-115$ alumino silicatos mesoporo Al-MCM-41, ${ }^{116}$ heteropoliácidos heterogêneos, ${ }^{52,117}$ carbono mesoporo sulfonado, ${ }^{118}$ sílicas mesoporosas funcionalizadas, ${ }^{119-122}$ montmorrillonita $\mathrm{KSF}^{123} \mathrm{e}$ compostos de cobre, ${ }^{81}$ além de zirconias modificadas. ${ }^{31,92,109,112,124-128} \mathrm{O}$ uso de catalisadores à base de antimônio, halfnio e zircônio na reação de transesterificação também são alguns dos exemplos, ${ }^{106,129-134}$ mas nenhum deles têm sido empregado em condições de fluxo contínuo ou na produção em larga escala de biodiesel até o presente.

Da mesma forma, muitos sólidos básicos heterogêneos têm mostrado alto potencial de uso na transesterificação para a produção de biodiesel, onde atualmente catalisadores alcalinos homogêneos são empregados. Porém, ainda existem muitos pontos a serem pesquisados, esclarecidos, estabelecidos e solucionados para que alguns desses compostos sejam aplicados na produção industrial de forma viável.

Via de regra os catalisadores básicos heterogêneos também fornecem bons rendimentos quando o meio reacional é submetido a altas temperaturas (acima de $200^{\circ} \mathrm{C}$ ) e pressão, embora existam umas poucas exceções, como é o caso do uso do metóxido de cálcio ${ }^{135}$ e o uso de alquilguanidinas suportadas em um polímero orgânico. ${ }^{136}$

Em trabalho de 1999, Gryglewics ${ }^{137}$ estudou de forma comparativa a atividade de catalisadores como o hidróxido de cálcio $(\mathrm{CaO})$, metóxido de cálcio $\left(\mathrm{Ca}\left(\mathrm{OCH}_{3}\right)_{2}\right)$; hidróxido de bário e óxido de magnésio. Esse autor usou como referência a reação de transesterificação com $\mathrm{NaOH}$ que mostrou a maior atividade catalítica.

No caso do metóxido de cálcio o autor observou que os ésteres metílicos do óleo de colza (canola) se formaram em 55\% de rendimento após 30 min de reação, aumentando para $80 \%$ após $1 \mathrm{~h}$, sendo $93 \%$ o rendimento máximo obtido 2,5 h após o início da reação. O óxido de magnésio e o hidróxido de cálcio não apresentaram atividade catalítica nas condições descritas.

Outro ponto que precisa ser estudado em maiores detalhes para muitos catalisadores sólidos básicos que têm mostrado boa atividade catalítica é se eles realmente atuam através de mecanismo catalítico heterogêneo ou não, determinando se são $100 \%$ insolúveis no meio reacional. É possível afirmar com bastante precisão, que alguns deles, assim como acontece com alguns catalisadores sólidos ácidos, perdem atividade por lixiviação, ${ }^{136}$ devido a algum grau de solubilidade no álcool ou na glicerina, ou ainda na mistura reacional como um todo, o que pode também resultar em uma parcela de contribuição à reação de transesterificação, promovida por mecanismo catalítico homogêneo. Neste caso a completa retirada, mesmo que de traços do catalisador residual nos produtos obtidos (biodiesel e glicerina), volta a ser uma preocupação para a aplicação industrial desses processos e para o uso do biodiesel. Embora com uma raríssima exceção ${ }^{126}$ até o presente, a maioria quase absoluta dos artigos científicos não tem tratado da possível presença e remoção desses catalisadores residuais devido ao processo de lixiviação.

Ao mesmo tempo, poucos autores afirmam em suas publicações que os catalisadores sólidos utilizados são $100 \%$ insolúveis e, portanto, realmente heterogêneos, garantindo a segurança do produto e a total recuperação do catalisador para reuso, como o fazem Bournay et al. com o aluminato de zinco ${ }^{90}$ ou Liu et al. com o metóxido de cálcio, ${ }^{135}$ ao qual é atribuída uma solubilidade máxima em metanol de $0,04 \% .^{138}$

No caso de catalisadores que contêm enxofre como, por exemplo, zircônia sulfatada, a lixiviação de sulfatos é uma das mais preocupantes, pois o aumento do teor de enxofre no biodiesel não é aceitável, em particular quando ele será usado como aditivo do diesel de baixo teor de enxofre. ${ }^{139}$

Outro item a ser considerado é o atendimento das características físico-químicas como, por exemplo, o teor de glicerina livre no produto final. A maioria dos trabalhos com catalisadores heterogêneos destaca a maior facilidade de separação de fases e da purificação do biodiesel, porém não menciona sequer como seria feita essa purificação.

Bournay et al. em seu primeiro depósito de patente também não o fizeram, ${ }^{140}$ mas em dois depósitos posteriores ${ }^{141,142}$ nos quais decrevem "melhorias" do processo, discutem o uso de membranas para remover grande parte do metanol em excesso e o uso de resinas de troca iônica para atender as especificações de qualidade EN 14214 do biodiesel obtido, reduzindo assim o teor de glicerina presente no biodiesel, mesmo após a separação "eficiente" das fases formadas.

Por último, deve-se levar em consideração que dependendo das condições experimentais específicas de aplicação, certos catalisadores ditos heterogêneos podem promover reações paralelas indesejadas como, por exemplo, a formação em grandes quantidades de $\mathrm{CH}_{3} \mathrm{OCH}_{3}$ que é um produto gasoso formado quando a zirconia sulfatada, por exemplo, é usada como catalisador sob alta temperatura e pressão ${ }^{127}$ ou em alguns casos como o do $\mathrm{CaO}$ que, por ser fortemente básico, não é tolerante à presença de AGLs transformando-os em sabão resultando ainda na perda da sua atividade catalítica. ${ }^{44,86}$ Este composto, por ser insolúvel em metanol ou etanol à temperatura ambiente, tem sido considerado um catalisador heterogêneo, ${ }^{44,86}$ porém em elevadas temperaturas mostra um certo grau de solubilidade, ${ }^{137}$ além do mais, o $\mathrm{CaO}$ é solúvel em glicerina e à medida que esta vai se formando no meio reacional pode ir solubilizando o catalisador. Assim sendo, junto à catálise heterogênea a atividade catalítica homogênea parece ter sua contribuição no processo.

Apesar disso, entre os óxidos metálicos descritos, o que mais atenção tem recebido pelos pesquisadores é o $\mathrm{CaO}$ que tem mostrado uma alta atividade catalítica na reação de transesterificação.

No trabalho realizado por Reddy et al., ${ }^{143}$ o uso de $\mathrm{CaO}$ nanocristalino resultou na formação de biodiesel em alto rendimento somente após 6-24 h de reação, sendo que o catalisador perdeu a sua atividade após 8 ciclos reacionais usando óleo de soja e após 3 ciclos usando gordura de frango.

Trabalhos posteriores, à base de combinações do $\mathrm{CaO}$ como CaO.MgO; ${ }^{144} \mathrm{CaO} . \mathrm{CeO}_{2} ;{ }^{145} \mathrm{CaO} . \mathrm{ZnO} ;{ }^{45} \mathrm{CaO}$ suportado em sílica mesoporosa, ${ }^{146}$ não mencionam sequer a possibilidade de perda de atividade catalítica por lixivição ou em função de uma possível reação com ácidos graxos livres que possam estar presentes. É possível que as características desses catalisadores sejam diferentes em função da mudança estrutural ao combinar $\mathrm{CaO}$ com óxidos de outros metais, podendo resultar em catalisadores totalmente heterogêneos. Porém, estabelecer com $100 \%$ de certeza a influência desses fatores é ainda uma necessidade, devendo-se levar em conta que segundo Granados et al., a reação catalítica empregando $\mathrm{CaO}$ ativado em metanol é o resultado de uma contribuição de mecanismos heterogêneo e também homogêneo. ${ }^{44}$

Outro ponto interessante diz respeito à real natureza ou composição química do catalisador, uma vez que há a possibilidade 
do metanol utilizado no processo reagir na superfície do óxido de cálcio formando metóxido de cálcio que atuaria como o verdadeiro catalisador. ${ }^{137,138}$

No caso do metóxido de cálcio $\mathrm{Ca}\left(\mathrm{OCH}_{3}\right)_{2}$, como catalisador heterogêneo, uma alta atividade durante o reuso foi observada mesmo após o vigésimo ciclo reacional. ${ }^{135} \mathrm{O}$ rendimento da transesterificação do óleo de soja com metanol foi descrito como $98 \%$ após $2 \mathrm{~h}$ de reação e a uma temperatura reacional de $65^{\circ} \mathrm{C} .{ }^{135}$

Além dos óxidos mistos de cálcio e de outros metais alcalinos, ou alcalino-terrosos, ${ }^{147}$ óxidos como os de estanho/zinco adsorvidos em alumina $\left(\mathrm{Al}_{2} \mathrm{O}_{3}\right)_{\mathrm{x}}(\mathrm{SnO})_{\mathrm{y}}(\mathrm{ZnO})_{\mathrm{z}}{ }^{148}$ ou óxidos de vanádio $\left(\mathrm{V}_{2} \mathrm{O}_{5} /\right.$ $\left.\mathrm{V}_{2} \mathrm{O} / \mathrm{VOOH}\right)^{82}$ também têm se mostrado ativos e eficientes fornecendo o biodiesel em elevados rendimentos. Nestes dois últimos casos as temperaturas reacionais foram a de refluxo do metanol $\left(\sim 65^{\circ} \mathrm{C}\right) \mathrm{e}$ pressão ambiente, mostrando um maior potencial de aplicação do que outros catalisadores sólidos básicos já descritos na literatura, como a hidrotalcita $\mathrm{MgCoAl}-\mathrm{LDH}$ que exige um aquecimento a $170{ }^{\circ} \mathrm{C}^{89}$ durante $5 \mathrm{~h}$.

No caso do uso de resinas de troca iônica e catalisadores com álcalis suportados, os grupos ativos são facilmente "corroídos" pelo álcool resultando em uma drástica diminuição do tempo de vida do catalisador. $^{148-150}$

O uso da zeolita ETS-10 ${ }^{102}$ como catalisador heterogêneo tem permitido $90 \%$ de transformação do óleo de soja quando a reação é realizada a $100{ }^{\circ} \mathrm{C}$, enquanto o uso de potássio suportado em alumina, transesterifica esse mesmo óleo em $87 \%$, após 7 h de refluxo e usando uma razão molar metanol: óleo de 15:1. ${ }^{85}$

Acreditamos haver aqui mais uma necessidade e, portanto, oportunidade de pesquisa, já que muitos desses catalisadores que perdem atividade ou massa devido à solubilidade (lixiviação) no meio reacional e que por isso precisam ser recuperados por "reativação" 45,109 podem estar atuando através de mecanismos reacionais homogêneos ao invés de heterogêneos, ou através dos dois mecanismos simultaneamente. Isso pode ocorrer com catalisadores recentemente descritos como zircônia sulfatada ${ }^{109,112,124-128}$ ou ainda com o $\mathrm{Ba}(\mathrm{OH})_{2}$ que é um dos catalisadores "heterogêneos" de maior atividade entre aqueles descritos até o presente, ${ }^{137}$ apesar do seu uso não ser recomendável devido à toxicidade desse composto de bário.

Mesmo que muitos processos com catalisadores homogêneos, heterogêneos, enzimáticos, hidrotalcitas básicas, guanidinas e óxidos metálicos, mostrem potencial, até o presente nenhum deles mostrou superioridade suficiente para substituir a aplicação prática dos alcoolatos isentos de água e comercializados prontos para o uso.

Enzimas imobilizadas em diversos suportes são outros catalisadores que promovem a transesterificação e algumas vezes a esterificação, podendo ser recuperados e reutilizados. As vantagens e limitações de uso de enzimas têm servido de oportunidade para o desenvolvimento do uso de células - integrais como biocatalisadores na maioria das vezes imobilizadas. O uso de ambos os sistemas catalíticos será discutido em detalhes a seguir.

\section{CATÁLISE ENZIMÁTICA E USO DE CÉLULAS- INTEGRAIS COMO CATALISADORES NA PRODUÇÃO DE BIODIESEL}

A transesterificação de triglicerídeos com um álcool, na presença de uma lipase extracelular ou intracelular tem sido utilizada para a produção de biodiesel, sendo que a maioria das pesquisas publicadas tem usado preparações comerciais de lipases extracelulares em sistemas reacionais pseudo-homogeneos e também na forma imobilizada. ${ }^{151-156}$

$\mathrm{O}$ uso de enzimas livres resulta em dificuldades técnicas, sendo praticamente impossível a recuperação e reuso das mesmas, o que incrementa os custos econômicos do processo, além de promover a contaminação do produto com atividade enzimática residual. ${ }^{154-156}$ Essas dificuldades podem ser superadas pelo uso dessas enzimas na sua forma imobilizada, permitindo o reuso desse biocatalisador várias vezes, reduzindo custos e ainda melhorando a qualidade do produto obtido. . $^{32,33}$

O confinamento ou localização física de uma enzima em uma determinada região de um espaço definido, com a manutenção das suas atividades catalíticas, podendo ser usada repetida e continuamente devido à facilidade de sua separação do meio reacional é que caracteriza a "imobilização" da mesma.

De forma geral, os métodos de imobilização enzimática podem ser agrupados em dois grandes grupos ou categorias, baseadas na chemsorption (adsorção, ligações iônicas, ligações covalentes) ou na retenção física (trapeamento e encapsulação). ${ }^{157}$ Essas técnicas de imobilização e outras técnicas, como a "imobilização híbrida", têm sido usadas na obtenção de catalisadores heterogêneos, visando a produção de biodiesel e foram recentemente revisadas em detalhe por Jegannathan et al. ${ }^{156}$

As atividades catalíticas e outras características das enzimas podem mudar dependendo do tipo de retenção (química ou física), da força da interação entre a enzima e o suporte utilizado que pode, em alguns casos, causar distorções estruturais na proteína. ${ }^{158}$ Ainda, a atividade catalítica da enzima em um determinado suporte pode ser alterada, aumentando ou diminuindo devido à fragmentação do suporte pela interação do sistema de agitação e o suporte.

Assim, durante a reação, a enzima pode ser removida do suporte devido a essa interação promovendo a "perda de atividade" no reuso, devido à lixiviação e não à inativação da enzima. ${ }^{159}$ Por outro lado, se essa lixiviação não ocorrer e a enzima permanecer ligada ao suporte, o aumento da superfície de contato poderá ajudar no aumento da transferência de massa, aumentando consequentemente a eficiência da enzima como catalisador. ${ }^{160,161}$

Lipases de diversas fontes têm sido imobilizadas e usadas na produção de biodiesel, porém as mais utilizadas pela maioria dos pesquisadores foram obtidas de Candida antarctica ${ }^{156,162}$ e Thermomyces lanuginosus. ${ }^{156,162}$

A produção enzimática do biodiesel pode ser realizada usando solventes orgânicos (geralmente hexano ou heptano) ou simplesmente usando a mistura dos substratos (lipídeos e álcool). Neste último caso, é recomendado que o álcool seja adicionado em pequenas porções, de forma a manter baixas concentrações do mesmo, evitando assim a inativação da enzima. ${ }^{163}$

Ésteres metílicos de ácidos graxos derivados de óleo de soja foram obtidos em sistemas livres de solvente usando lipases de $C$. antarctica (Novozym 435), T. lanuginosa (Lipozyme TL IM) e $R$. miehei (Lipozyme RM IM) por Xu et al. ${ }^{164}$ e mais recentemente as três mesmas enzimas foram usadas por Rodrigues et al. ${ }^{165}$ na alcoólise dos óleos de soja, girassol e de arroz, empregando metanol, etanol, propanol e butanol.

O óleo de soja foi transesterificado com etanol em sistema livre de solvente, sob catálise enzimática de $M$. miehei ou P. cepacia. ${ }^{166}$ Neste mesmo trabalho, essas enzimas também foram usadas na transesterificação com metanol, porém na presença de hexano como solvente. ${ }^{166}$

A transesterificação do óleo de girassol com metanol e com butanol foi realizada eficientemente ${ }^{167}$ usando hexano como solvente e a lipase Rhizomucor miehei (Lipozyme RM IM), assim como com a lipase de Aspergillus niger, C. rugosa, P. cepacia, $R$. oryzae, e $P$. fluorences. ${ }^{168} \mathrm{O}$ mesmo óleo foi transesterificado com metanol na ausência de solvente, usando as lipases de $R$. miehei, P. fluorences e T. lanuginosa. ${ }^{168}$

No caso do óleo de colza a catálise da reação de transesterificação com as lipases de T. lanuginosa (Lipozyme TL IM) e M. circinelloides 
usando metanol foi realizada sem o auxílio de solventes orgânicos, enquanto as lipases da $M$. miehei e da Mucor circinelloides foram usadas na metanólise e na etanólise auxiliadas pelo uso de hexano como solvente. ${ }^{162,169}$

As enzimas da $C$. antarctica e da $M$. miehei ${ }^{166}$ foram usadas em um sistema livre de solvente e auxiliado por hexano, respectivamente, na transesterificação do sebo animal, com metanol e etanol no último caso e com isopropanol e 2-butanol no caso de $C$. antarctica.

Analisando a literatura, pode-se verificar que em muitos artigos, o uso de catalisadores enzimáticos para a produção de biodiesel empregando lipases extracelulares, tanto na transesterificação como na interesterificação, tem sido usado como uma alternativa que ajudaria a superar os problemas que são contínua e comumente associados à catálise homogênea alcalina.

Esse argumento tem sido sistematicamente repetido na literatura por muitos autores, afirmando que o uso de biocatalisadores é atrativo, pois o biodiesel obtido enzimaticamente poderia ser usado diretamente sem a necessidade de nenhuma purificação. ${ }^{14,165,166,170}$ Porém, isso deve ser melhor avaliado, uma vez que mesmo se o rendimento da transformação fosse $100 \%$, fato incomum na catálise enzimática até o presente, após a separação da glicerina, a fase que contém os ésteres deverá ser submetida à evaporação para a completa remoção do álcool que foi usado em excesso. No caso de ter sido usado um cossolvente como, por exemplo, hexano ${ }^{171,172}$ este também deverá ser removido. Os ésteres resultantes ainda poderão conter glicerina residual dissolvida, a qual deverá ser removida em uma etapa de purificação obrigatória para enquadrar o produto nas especificações de qualidade EN 14214, ${ }^{6}$ ASTM 6751 D $^{4}$ ou ANP 07/2008. ${ }^{8}$

Ainda, entre os fatores que limitam a aplicação em larga escala dos processos enzimáticos temos o fato dos tempos reacionais serem muito longos ${ }^{162} \mathrm{e}$ as transformações (e rendimentos) serem ainda baixas ou distantes dos 99-100\% desejados, o que resulta em monoglicerídeos, diglicerídeos e, às vezes, triglicerídeos no produto final. ${ }^{162}$ A presença dessas substâncias dificulta ainda mais o cumprimento das especificações físico-químicas de qualidade, o que exigiria a repetição do processo reacional, aplicando uma segunda reação para a total conversão em biodiesel ou em contrapartida, introduzir uma etapa de separação/purificação como, por exemplo, o uso da destilação sob vácuo, que consumiria energia e aumentaria os custos do produto.

Além desses pontos, existem tópicos que precisam ser melhor estudados como, por exemplo, o efeito da água na reação de transesterificação enzimática. Segundo alguns trabalhos, um conteúdo de água mínimo de $0,48 \%$ em peso é necessário para promover a ativação das enzimas, ${ }^{173-176}$ em função da formação de gotas água-óleo que aumentam a área interfacial disponível. Por isso alguns trabalhos propõem a adição de água para ativar a enzima. ${ }^{177}$ Em contrapartida, o volume mínimo de água para essa ativação equivale a pelo menos dez vezes o teor de água permitido (500 ppm) para o biodiesel nas especificações de qualidade, ${ }^{4-8} \mathrm{o}$ que poderia tornar necessária a adição de mais uma etapa no processo, a de secagem do biodiesel.

Por outro lado, alguns pesquisadores têm descrito um decréscimo na produção dos ésteres quando a adição de água é realizada. ${ }^{172,178}$ É necessário levar em consideração, ainda, que algumas enzimas imobilizadas disponíveis comercialmente possuem uma quantidade significativa de água em seu suporte, proveniente do processo de imobilização, o que torna a discussão mais polêmica no que diz respeito à necessidade de secagem, ou não, destas enzimas, antes de utilizá-las no processo de transesterificação.

Não se deve esquecer que em meio aquoso as enzimas promovem a hidrólise, que competirá com a transesterificação, portanto, o teor de água ideal deve ser cuidadosamente estudado para minimizar a hidrólise e maximizar a atividade enzimática para a reação de transesterificação. ${ }^{179}$
Desta forma, na área de biocatálise também são necessários muitos avanços para que a sua utilização ganhe aplicação prática e competitiva, uma vez que as vantagens oferecidas por esses processos, e discutidos na literatura, ainda não têm se mostrado suficientes para atingir o objetivo desejado de substituir a catálise alcalina homogênea na escala industrial.

Mesmo aceitando o grande potencial das lipases imobilizadas em resinas acrílicas ou em outros suportes e encontrando as soluções desejadas que promovam altos rendimentos das transformações, reduzindo os tempos reacionais e solucionando as limitações técnicas já mencionadas, o custo elevado desses biocatalisadores ainda faz com que este processo seja restritivo em termos econômicos para a aplicação comercial. Nestes casos tem-se utilizado como justificativa o fato dos catalisadores enzimáticos poderem ser reutilizados por vários ciclos sem perda de atividade ou com perda desprezível. Alguns autores sugerem técnicas de reativação das mesmas com o auxílio de solventes orgânicos. ${ }^{152}$

Para reduzir os custos dos processos enzimáticos alguns pesquisadores têm estudado a imobilização de micro-organismos como micélios fúngicos, bactérias e leveduras e o uso deles como catalisadores de "célula integral" aproveitando as proteínas funcionais de interesse na superfície celular.

Da mesma forma, a expressão de enzimas do tipo lipases na superfície de células de leveduras foi desenvolvida para criar biocatalisadores de "célula integral" para aplicações industriais. ${ }^{180,181}$

O primeiro exemplo de produção de biodiesel usando uma célula integral como biocatalisador foi descrito por Ban et al. ${ }^{182}$ Esses autores imobilizaram micélios de $R$. oryzae em espuma de poliuretano. As condições de cultivo foram otimizadas em relação à produção com lipases intracelulares, assim como os métodos de pré-tratamento e o do conteúdo de água na metanólise. A adição de compostos substratosrelacionados com o meio de cultura melhora significativamente a atividade da lipase do catalisador de célula integral. Os resultados para a obtenção dos ésteres metílicos de soja (72\% de rendimento) usando este catalisador a $32{ }^{\circ} \mathrm{C}$ durante $72 \mathrm{~h}$, quando a adição do metanol ao meio foi feita em etapas, ${ }^{182}$ foram muito similares àqueles descritos com o uso de lipases extracelulares. ${ }^{183}$

Transesterificação similar do óleo de soja com metanol na ausência de solvente à temperatura ambiente empregando a $R$. oryzae imobilizada $^{184}$ resultou nos ésteres metílicos com um rendimento melhorado (90\%) e uma redução do tempo reacional para 48 h. No caso do óleo de pinhão manso (Jatropha curcas), esse mesmo biocatalisador foi usado na ausência de solvente a $30^{\circ} \mathrm{C}$, durante $60 \mathrm{~h}$, resultando nos ésteres metílicos desejados em $89 \%$ de rendimento. ${ }^{185}$

Por outro lado, Li et al. ${ }^{186}$ estudaram a transesterificação do óleo de colza bruto, refinado e também acidificado. Nos três casos foi usado t-butanol como solvente e a reação foi realizada a $35^{\circ} \mathrm{C}$ durante $24 \mathrm{~h}$, resultando nos ésteres metílicos correspondentes em rendimentos modestos de 60,60 e $70 \%$, respectivamente.

Outras células integrais como o micélio de $R$. chinensis, ${ }^{187} \mathrm{~S}$. cerevisae (ROL intracelular), ${ }^{180} \mathrm{~S}$. cerevisae recombinante com expressão de gene da lipase da $R$. oryzae (ROL na superfície da célula) ${ }^{181}$ têm sido usadas como biocatalisadores na produção de biodiesel metílico de soja, na ausência de cossolvente, resultando na produção de biodiesel com rendimentos de 86,71 e $78 \%$, respectivamente.

Outro trabalho interessante descreve o desenvolvimento do Aspergillus oryzae recombinante como biocatalisador de célula integral, com a expressão do gene que codifica a lipase Candida antarctica. ${ }^{188}$

Os resultados descritos até o presente mostram interessantes potencialidades de uso, em função da facilidade de recuperação e reuso, a baixas temperaturas requeridas, condições reacionais suaves com baixo consumo energético e pH não agressivo. Porém, é necessário 
realizar uma série de estudos que resultem na melhoria da velocidade de reação, reduzindo o tempo de transesterificação e fornecendo os produtos em rendimentos mais altos, com transformações mais eficientes, de forma a possibilitar aplicações industriais práticas e competitivas. Além disso, trabalhos futuros deverão focar também nas propriedades físico-químicas dos ésteres produzidos por via enzimática ou por catálise usando células integrais.

Acreditamos que no futuro haverá um incremento no interesse para a produção in vivo de "biocombustíveis avançados" como alcanos, alcenos, aromáticos, mono-ésteres alquílicos de ácidos graxos (biodiesel) usando micro-organismos ou espécies vegetais. Entretanto, isso requerirá modificações feitas através de engenharia genética $^{189-191}$ ou alternativamente reestruturar (ou reinventar) o metabolismo dessas espécies. ${ }^{192-194}$ Neste sentido, enormes esforços precisam ser feitos para atingir micro-organismos hospedeiros com produção otimizada, devendo-se levar em conta que a inerente complexidade dos micro-organismos representa um enorme desafio para a engenharia celular.

Ésteres butílicos de ácidos graxos e de ésteres-cera similares aos encontrados in vivo, pela biossíntese do óleo de jojoba, foram recentemente produzidos através da Escherichia coli engenheirada, conforme descrito por Kalscheuer et al. ${ }^{195}$ Embora as quantidades de mono-ésteres alquílicos de cadeia longa (ceras) produzidos sejam ainda muito baixas, o trabalho descreve claramente a produção biotecnológica de lipídeos semelhantes aos do óleo de jojoba a partir de fontes naturais baratas e renováveis, como ácidos graxos empregando micro-organismos recombinantes.

O mesmo grupo de pesquisa estabeleceu ${ }^{196}$ a biossíntese de ésteres etílicos de ácidos graxos, os quais foram chamados de "microdiesel", usando a Escherichia coli metabolicamente modificada pela expressão heteróloga da Zymomonas mobilis piruvato descarboxilase e da aciltransferase inespecífica da Acinetobacter baylyi da linhagem ADP1. A coexpressão de três genes relevantes nesse experimento resultou na formação de $26 \%$ de ésteres etílicos de ácidos graxos em relação ao peso celular seco, o que representa um avanço científico significativo.

Porém, esta rota biotecnológica ainda está longe de ser a ideal para a produção de biodiesel, pois, tal biossíntese se mostrou estritamente dependente da suplementação exógena de oleato de sódio (adição ao meio reacional), garantindo a formação do oleato de etila. Além disso, pequenas quantidades de palmitato de etila ou palmitoleato de etila foram também identificadas, o que indica que algum substrato acila intracelular é canalizado para produção de ésteres etílicos. Ainda, para evitar limitações (falta) de carbono e por consequência do etanol produzido pela $E$. coli, necessário à reação de transesterificação, os autores realizaram a adição de glucose ao meio, várias vezes durante o período de cultivo.

Apesar dos resultados destes trabalhos serem altamente promissores, pesquisas intensivas ainda são necessárias para possibilitar a produção de biocombustíveis de forma economicamente viável. Com os avanços tecnológicos e científicos, os trabalhos acadêmicos neste campo deverão se mover além da fase da "descoberta" para a aplicação e implementação do conhecimento de abordagens de sistemas biológicos no campo da engenharia metabólica que permita uma produção consistente, além de aplicações industriais em larga escala.

Por isso, fica como desafio futuro para os pesquisadores, a academia e a indústria, com o advento de novas técnicas genômicas funcionais, ou com base no crescimento heterotrópico capaz de provocar mudanças nos metabolismos envolvidos sob condições de crescimento restrito, como stress ou falta severa de nutrientes,${ }^{197,198}$ conseguir a produção e acúmulo intracelular de lipídeos como triglicerídeos ou mono-ésteres alquílicos de ácidos graxos em teores elevados, em determinadas plantas ou micro-organismos como algas ou bactérias.
A comunidade científica internacional tem discutido constantemente nos últimos anos o potencial de produção em larga escala industrial de etanol a partir de materiais lignocelulósicos. Acreditamos também que o desenvolvimento de biotecnologias inovadoras será fundamental para a produção deste tipo de bioenergia e de outras como o biodiesel. Neste sentido, sem ter datas exatas no horizonte, pode-se vislumbrar um grande direcionamento futuro das pesquisas acadêmicas com o intuito de produção de biodiesel e de outros biocombustíveis em larga escala, usando técnicas como: processamento ou pré-processamento in vivo (por exemplo, Sacaromices cerevisae e Escherichia coli); processamento ou pré-processamento in planta; produção in vivo (triglicerídeos e/ou biodiesel); produção in planta (sesquiterpenos, triglicerídeos e/ou biodiesel).

Esses quatro itens poderão trazer as maiores e melhores soluções para a produção de bioenergia, através do que poderemos chamar de biotecnologia de plantas e de micro-organismos para a produção de biocombustíveis líquidos.

\section{MATÉRIAS-PRIMAS}

Embora seja claro que avanços tecnológicos significativos ainda devam ser alcançados para transformar o biodiesel em um produto realmente sustentável e economicamente competitivo, ${ }^{33,197,198}$ devemos considerar que na atualidade isso ainda não acontece, pois a despeito dos impactos ambientais, sociais e outros altamente favoráveis que a produção, comercialização e o uso do biodiesel podem provocar, a viabilidade econômica do mesmo é freada pelos altos preços das matérias-primas oleaginosas ${ }^{33,197,198}$ em maior extensão do que por limitações tecnológicas ou do processamento.

Esta análise mostra uma grande necessidade e, portanto, uma oportunidade de pesquisa e desenvolvimento no campo acadêmico e industrial na busca pelo recurso natural mais adequado e disponível em larga escala para a produção de biodiesel. É importante levar em consideração que os óleos vegetais como matérias-primas para biodiesel competem com o uso como alimentos e no setor químico, além da quase inexistência de experiência agronômica com a maioria das oleaginosas, o que exige investimentos em estudos de impactos socioeconômicos e em pesquisas agronômicas.

É geralmente aceito que as matérias-primas usadas para a produção de biodiesel podem incluir qualquer óleo vegetal disponível (refinados, semi-refinados, degomados, crús e até alguns não comestíveis), óleos produzidos por micróbios e óleos de frituras usados, inclusive gorduras natural ou artificialmente hidrogenadas, sebo bovino, banha, gordura de frango, óleos de peixes. ${ }^{162}$

Porém, é de fundamental importância relacionar a estrutura química e os teores de cada uma das substâncias presentes na matériaprima, pois estas refletirão não só nas propriedades físico-químicas do biocombustível, mas poderão afetar a queima no motor, a formação de depósitos no sistema de injeção e ainda o tipo e a quantidade de substâncias ou gases poluentes emitidos.

A composição química de alguns óleos tem sido objeto de revisões na literatura, ${ }^{9,12,33}$ podendo servir de base para uma análise preliminar sobre a viabilidade ou não do seu uso como matéria-prima para a produção de um biodiesel que atenda completamente as especificações de qualidade..$^{4-8}$

De qualquer forma, a disponibilidade de óleos ou gorduras em grandes quantidades e a preços competitivos é um desafio tão grande quanto vencer qualquer limitação científica ou tecnológica que possa existir na atualidade. No longo prazo, cultivos perenes e de elevados rendimentos por unidade de área são desejáveis e preferíveis em relação a cultivos anuais e de ciclo curto como matérias-primas para a produção de bioenergia, pois não precisam ser replantados a cada estação e porque também requerem menor uso de fertilizantes, 
defensivos agrícolas (herbicidas, pesticidas e outros) e até irrigação, causando a consequente redução dos custos de produção. Devem ser ainda levadas em consideração as diferenças no custo entre colheitas mecanizadas da maioria dos cultivos de ciclo curto e o da coleta manual que é exigida por plantas como o dendê e o pinhão manso.

Recentemente, a Jatropha curcas tem sido cultivada em muitas partes do mundo ${ }^{63,80,199-202}$ como Egito, Índia, Brasil e outros países. Os seus frutos fornecem um óleo não comestível, mas que pode ser usado como matéria-prima para a produção de biodiesel. ${ }^{80,199-202}$

Os fatores importantes e que deverão nortear as pesquisas, os avanços e, consequentemente, o sucesso do biodiesel no que diz respeito à escolha da matéria-prima são: composição química do óleo extraído da fonte em questão; elevado rendimento energético por unidade de área; produção abundante de óleos a custos reduzidos.

Os dois últimos itens são de extrema importância quando se pensa em termos de competitividade econômica, uma vez que produtividades agrícolas na faixa de 400 a $500 \mathrm{~kg} /$ hectare/ano como é o caso da soja no Brasil e nos Estados Unidos, ou de 500 a 900 kg/hectare/ ano para a colza (canola) na Europa, inviabilizam economicamente a produção de biodiesel e por isso o subsídio é inevitável. Já no caso da palma africana (dendê) rendimentos de até $6.000 \mathrm{~kg} / \mathrm{hectare} / \mathrm{ano}$ podem ser conseguidos e o potencial de produção ainda é maior com o uso de algumas algas como ainda será discutido neste artigo.

Muitas publicações recentes na literatura descrevem a produção de biodiesel das mais diversas fontes e plantas. Porém, os pesquisadores têm focado a sua atenção na transesterificação ou na esterificação desses materiais para, posteriormente, determinar se as propriedades físico-químicas do biodiesel (metílico ou etílico) obtido a partir de determinada matéria-prima se enquadram ou não dentro dos parâmetros estabelecidos nas normas de qualidade ASTM 6751 D, EN 14214, ANP 07/2008.

A maioria absoluta desses artigos tem usado catalisadores clássicos como $\mathrm{NaOH}$ ou $\mathrm{H}_{2} \mathrm{SO}_{4}$ para transesterificar ou esterificar essas "novas matérias-primas", o que não está relacionado com nenhum desenvolvimento científico-tecnológico da produção da matéria-prima nem do processo produtivo do biodiesel, mas com a simples preparação do biodiesel e a determinação de alguns dos seus parâmetros físico-químicos. Exemplo disso são artigos que têm empregado óleo crú de peixes marinhos ${ }^{56}$ ou plantas como a karanja, ${ }^{60}$ o Tucum ${ }^{55} \mathrm{e}$ outras que, apesar de conhecidas, não têm produção comercial como é o caso do óleo de seringueira, ${ }^{34}$ da semente do tabaco ${ }^{35}$ e ainda algumas que têm produção de óleo marginal em termos de oferta no mercado, como é o caso do gergelim. ${ }^{61,203}$

Porém, a necessidade real é poder contar com matérias-primas abundantes, baratas e de composição química adequada que permitam atender os parâmetros de qualidade do biodiesel em termos físicoquímicos. Estes parâmetros estão muito bem definidos técnica e cientificamente, o que permite ao químico prever se uma determinada matéria-prima é apropriada ou não para a produção de um biodiesel que atenda os parâmetros de qualidade desejados, baseando-se na sua composição química.

Neste sentido, conhecer a composição química detalhada do óleo ou gordura, seja qual for a sua origem, é muito mais importante do que simplesmente realizar a transesterificação em escala de laboratório como tem acontecido na literatura. ${ }^{34,35,55,56,60,61,203}$ Isto porque a qualidade (características físicas e químicas) do biodiesel obtido é função direta da composição química do óleo ou gordura usado como material de partida.

Algumas substâncias podem e devem ser removidas ainda no material de partida antes da transesterificação como, por exemplo, ácidos graxos livres, água, fosfolipídeos, ceras.

Água e AGLs são prejudiciais à reação de transesterificação sob a grande maioria das condições reacionais e processos conhecidos (enzimáticos, alcalinos, ácidos, sejam homo ou heterogêneos). Portanto, a remoção dessas substâncias é muito importante antes da transesterificação.

No caso de existir um catalisador compatível com a presença de água, ela ainda terá que ser removida durante o refino do biodiesel que deverá conter no máximo 500 ppm $(0,05 \%)$ de água para o seu uso como combustível. ${ }^{4-8}$ Se o catalisador for compatível com a presença de ácidos graxos, mas não é capaz de promover a esterificação dos mesmos, esses AGLs deverão ser removidos posteriormente durante o refino do biodiesel, pois o limite máximo de $0,5 \mathrm{mg} \mathrm{KOH} / \mathrm{g}$ precisa ser atendido. ${ }^{4-8}$

\section{Fosfolipídeos}

Comumente chamados de gomas, devem ser removidos antes da transesterificação, pois podem consumir o catalisador impedindo que a transesterificação seja completa, além de promover a formação de emulsões comprometendo a separação de fases ésteres/glicerina e principalmente ésteres/água. Embora o uso de maiores quantidades de catalisador (se alcalino) permita a transesterificação completa, se as gomas estiverem presentes no biodiesel, as fases sofrerão emulsificação durante a lavagem, o que forçaria a realização de degomagem do biodiesel. Além disso, o teor de fósforo no biodiesel deve ser inferior a $10 \mathrm{mg} / \mathrm{kg}^{4-8}$

\section{Ceras}

Embora as ceras não sejam reguladas nas especificações de qualidade, influenciam na formação de precipitados e sobrenadantes, além de influenciar a temperatura do ponto de névoa.

Óleos como o de girassol, amendoim, arroz e algodão podem apresentar esse tipo de situação caso as ceras não sejam removidas através do refino do óleo. Em alguns óleos como o de jojoba é muito comum encontrar ésteres cera ${ }^{195}$ com cadeias hidrocarbônicas entre 38 e 44 átomos de carbono ( de $\left.\mathrm{C}_{38: 2} \mathrm{a} \mathrm{C}_{44: 2}\right)$.

No biodiesel do óleo de arroz pode ser encontrado o lignocerato derivado do ácido lignocérico $\left(\mathrm{C}_{24: 0}\right)$ embora em percentuais ao redor de $0,35-0,55 \%$. No caso do biodiesel metílico de amendoim observouse, em trabalho desenvolvido pelo nosso grupo de pesquisa, que o ponto de névoa medido através da norma ASTM D2500-05 foi de $21{ }^{\circ} \mathrm{C}$. Este fato foi atribuído à presença do ácido behenico $\left(\mathrm{C}_{22: 0}\right) \mathrm{em}$ $4 \%$ e lignocérico $\left(\mathrm{C}_{24: 0}\right)$ em $3 \%$ na sua composição. Ambos foram identificados por $\mathrm{CG} / \mathrm{MS}$ após serem concentrados por esfriamento a $12{ }^{\circ} \mathrm{C}$, seguido de centrifugação e separação do sólido (a frio) do sobrenadante. ${ }^{204}$

Portanto, é necessário conhecer o perfil de ácidos graxos, assim como a presença de outras substâncias na composição química de uma determinada matéria-prima, para entender a priori as características do biodiesel que pode ser obtido a partir da mesma, conforme será discutido nos próximos itens. Assim, será possível entender porquê nem todas as espécies que produzem óleos vegetais servem como matérias-primas para biodiesel, e como escolher as mais adequadas, uma vez que a composição química do óleo seria suficiente para mostrar se o biodiesel derivado atenderá ou não às especificações de qualidade. ${ }^{4-8}$

\section{Ácidos graxos saturados}

Pela especificação ASTM PS 121-99, o biodiesel deve ser composto por ésteres de cadeias hidrocarbônicas entre $\mathrm{C}_{12} \mathrm{e} \mathrm{C}_{22}{ }^{5} \mathrm{~A}$ planta de origem indiana Ximenia americana linn ${ }^{205}$ que contém $50 \%$ de óleo vegetal com índice de iodo 76 e número de cetano 61,4, aparentemente, seria uma excelente opção para a produção de biodiesel. Porém, ao se analisar a composição química do óleo observa-se a presença de 15,2\% de ácido cerótico $\left(\mathrm{C}_{26: 0}\right)$ e 14, 6\% de ácido de ximênico $\left(\mathrm{C}_{22: 4}\right)$, permitindo concluir que os mono-ésteres derivados não se 
enquadrariam na definição de biodiesel não só pelas cadeias maiores do que $\mathrm{C}_{22}$, mas também porque não atenderiam à especificação de 90 a $95 \%$ do limite do ponto de ebulição estar abaixo de $360{ }^{\circ} \mathrm{C}$ como especificado na norma ASTM 6751D e outras especificações de qualidade para B100.4-8 Os biodieseis mais comuns como o de soja, canola, dendê, girassol e outros com cadeias hidrocarbônicas de $\mathrm{C}_{16}$ a $\mathrm{C}_{18}$ têm pontos de ebulição na faixa $330-357^{\circ} \mathrm{C}$, atendendo facilmente às especificações.

Além disso, ésteres monoalquílicos de ácidos graxos com cadeias hidrocarbônicas acima de $\mathrm{C}_{20}$, assim como cadeias saturadas de $\mathrm{C}_{16}$ (palmítico) e $\mathrm{C}_{18}$ (esteárico), têm uma tendência maior a se solidificarem a baixa temperatura do que as cadeias de até 18 carbonos com uma ou mais insaturações podendo, portanto, tornar o biodiesel impróprio para o uso em climas frios. Essa característica (tendência a solidificar-se) é medida através do ponto de névoa (PN), ${ }^{4}$ mas o ponto de entupimento do filtro a frio (PEFF) também pode ser usado. ${ }^{6}$

As cadeias saturadas em contrapartida têm a vantagem de apresentar uma maior estabilidade à auto-oxidação fazendo com que parâmetros de estabilidade à oxidação, medidos pelo método Rancimat, ${ }^{6}$ sejam atendidos mais facilmente do que no caso da presença majoritária de cadeias insaturadas ou poli-insaturadas. Da mesma forma, o índice de iodo também será mais baixo, ajudando no cumprimento do limite máximo de $120 \mathrm{~g} \mathrm{I} / 100 \mathrm{~g}$ de amostra.

$\mathrm{O}$ ponto de névoa não elimina a possibilidade de uso dos ésteres obtidos a partir de óleos com cadeias saturadas $\left(\mathrm{C}_{16}\right.$ e $\left.\mathrm{C}_{18}\right)$ serem utilizados na produção de biodiesel, mas limita seu uso em forma pura ou em misturas maiores que B20 apenas a climas tropicais. Exemplo disso são os biodieseis de palma africana (dendê) e sebo (bovino). A disponibilidade destas matérias-primas, apesar da desvantagem do ponto de névoa, tem levado cientistas, técnicos e engenheiros a procurar um equilíbrio das características físico-químicas para o biodiesel produzido.

Uma dessas caracteristicas é o número de cetano (NC), responsável pela ignição e queima do combustível de forma eficiente (resultando em uma maior potência). Este será maior de acordo com o aumento do grau de saturação do biodiesel. Para evitar que o NC muito alto resulte em um PN e em um PEFF inadequados, as normas americanas $^{4,5}$ (ASTM 6751D PS121-99) têm limitado o NC ao valor máximo de 65 .

\section{Ácidos graxos insaturados}

A presença de cadeias insaturadas ameniza a possibilidade de gelificação ou solidificação do biodiesel e, portanto, o PN e o PEFF serão um inconveniente menor em climas frios.

O aumento do teor de ácidos graxos, com uma, duas, ou mais duplas ligações aumenta o grau de insaturação total do biodiesel que nas especificações de qualidade ${ }^{6}$ é medido pelo índice de iodo, limitado a $120 \mathrm{~g} \mathrm{I}_{2} / 100 \mathrm{~g}$ óleo para uso veicular e $130 \mathrm{~g} \mathrm{I} / 100 \mathrm{~g}$ para óleo de aquecimento, de acordo com as especificações européias. Estes limites estão baseados no fato da presença de posições alílicas $\left(\mathrm{CH}_{2}\right.$ vizinhos às duplas ligações) reagirem com o oxigênio atmosférico por via radicalar, formando peróxidos que se decompõem dando origem a compostos de cadeia carbônica menores como, por exemplo, aldeídos. O maior problema decorrente da decomposição dos peróxidos é a possibilidade de reação dos radicais livres com os sítios insaturados através de ligações cruzadas, dando origem a materiais poliméricos que causariam depósitos nos sistemas de injeção dos motores, os bicos injetores, ou promovendo o travamento do cabeçote da bomba de injeção de combustível.

A tendência à polimerização é mensurada nas especificações EN 14214 e ANP 07/2008 através do método Rancimat que indica maior ou menor estabilidade à oxidação. ${ }^{6,8}$ Porém, outro fator de suma importância em relação à estabilidade à oxidação está rela- cionada mais uma vez com a composição química do óleo vegetal usado como matéria-prima. A presença de teores elevados de ácido linolênico $\left(\mathrm{C}_{18: 3}\right)$ ou ácidos graxos com 4 ou mais insaturações no óleo resultará em uma tendência muito elevada a se oxidarem em função da presença de posições metilênicas bis-alílicas, que são muito mais reativas do que os metilenos alílicos mencionados. ${ }^{206}$

Em função disso, na norma EN 14214, os teores de ácido linolênico são limitados a no máximo $12 \%$ e poli-insaturados com mais de 4 duplas ligações a no máximo $1 \%$, fato que limita o uso de certas matérias-primas para a produção de um biodiesel com a qualidade exigida.

Um exemplo de óleo inapropriado é o de alguns peixes marinhos que contêm elevados teores de ácidos graxos Omega-3 poli-insaturados, como o docosa-hexanóico (DHA, $\mathrm{C}_{22: 6}$ ) ${ }^{56}$ Plantas também apresentam limitações nesse sentido, como é o caso da Swietenia maha goni Jacq. de origem indiana que apesar do conteúdo de óleo nos seus frutos ser de aproximadamente 50\%, o mesmo não é adequado para a produção de biodiesel, mesmo apresentando índice de iodo de 94 e número de cetano de 52, uma vez que o conteúdo de ácido linolênico $\left(\mathrm{C}_{18: 3}\right)$ na sua composição química é extremamente alto, atingindo $16,1 \%$ conforme descrito na literatura. ${ }^{207}$

Um óleo mais familiar com características similares é obtido das sementes da seringueira (rubber seed oil) que contêm de 40 a $50 \%$ de óleo vegetal em massa, apresentando uma cor marrom quando bruto. Este óleo foi transformado em ésteres metílicos pela combinação da esterificação e da transesterificação. ${ }^{34}$ Os autores desse trabalho descrevem que muitos parâmetros físico-químicos se enquadram nas especificações ASTM 6751D, embora a composição química em termos de ácidos graxos mostre um conteúdo de 80,5\% de componentes insaturados $\left(\mathrm{C}_{18: 1}, \mathrm{C}_{18: 2}, \mathrm{C}_{18: 3}\right)$, dos quais $16,3 \%$ correspondem ao ácido linolênico $\left(\mathrm{C}_{18: 3}\right)$. Estes autores não levaram em consideração o limite máximo de $12 \%$ exigido na norma européia EN 14214, nem determinaram o índice de iodo que pela composição química apresentada deverá ser superior a 140 g I/ $/ 100 \mathrm{~g}$ de amostra. A estabilidade à oxidação, que com certeza ficará altamente comprometida, também não foi determinada.

A composição química em ácidos graxos e os teores individuais de cada um destes influenciarão também em outros parâmetros, porém de forma menos crítica, como é o caso da viscosidade e da densidade. Estes parâmetros avaliados no produto final (biodiesel) sofrerão maior influência ainda, caso outras substâncias como mono, di, triglicerídeos e glicerina livre estejam presentes.

Percebe-se, portanto, que a simples análise da composição química dos óleos é suficiente para se inferir sobre possibilidades, potenciais e adequação do uso de uma determinada matéria-prima quanto à produção de um biodiesel de alta qualidade, assim como pode ser observado no artigo publicado por Sahoo et al.,${ }^{64}$ que descreve o biodiesel da semente de polanga e a comparação da sua composição química com os óleos de karanja, Jatropha, borracha e algodão.

No caso das algas, muitas especulações têm surgido quanto às suas potencialidades na produção de biodiesel. Existem composições químicas descritas para algumas delas que indicam a presença de até $55,3 \%$ de ácido linolênico $\left(\mathrm{C}_{18.3}\right)$, como é o caso da Spirulina platensis. ${ }^{208,209}$

Espécies como a Chlorella kesslen, Chlorella vulgaris e Scenedemus obligines produzem elevados teores de ácidos graxos insaturados, e em particular poli-insaturados, ${ }^{210,211}$ quando cultivadas na presença de dióxido de carbono. Esses resultados ${ }^{210,211}$ indicam que esses óleos têm elevada tendência à oxidação (polimerização), não sendo apropriados à produção de biodiesel.

Alguns artigos que descrevem resultados laboratoriais ou teóricos têm indicado que muitas microalgas possuem a capacidade de produzir quantidades consideráveis de triglicerídeos, podendo variar de 
20 a 50\% do peso da célula seca. Esses cálculos teóricos, de forma entusiasta, indicam que poderia ser obtido o equivalente de até 30.000 $\mathrm{L}$ de óleo por hectare. Porém, os rendimentos obtidos até o presente são de no máximo 10 ou 20\% desse máximo teórico. ${ }^{212}$

Existem mais de 40.000 espécies de microalgas já identificadas e muitas outras por identificar, além de cianobactérias que por simplificação e semelhanças também são chamadas de algas. ${ }^{212}$ As algas são classificadas em grandes grupos como: algas verdes (Chlorophyceae), algas verde-amarelas (Xanthophyceae), algas vermelhas (Rhodophyceae), algas marrons (Phaeophyceae), cianobactérias (Cyanophyceae), dinoflagelatos (Dinophyceae) e pico-plâncton (Prasinophyceae e Eustigmatophyceae), além de outras divisões adicionais e classes de algas unicelulares já descritas. ${ }^{213}$

Entre diversos grupos taxonômicos, podem ser encontradas algas oleaginosas, porém o conteúdo lipídico nas mesmas e a composição química dos óleos variam significativamente. A capacidade intrínseca de produzir óleo em grandes quantidades é específica de espécies individuais e de algumas linhagens não sendo, entretanto, específica do gênero. ${ }^{214}$ Por exemplo, algas verdes oleaginosas apresentam em média $27 \%$ do peso da célula seca em óleo, percentual que pode se duplicar ou triplicar quando são cultivadas sob condições de stress (foto-oxidativo ou falta de nutrientes específicos). Já no caso de cianobactérias, apesar de serem capazes de produzir lipídeos, estes não ocorrem e nem são acumulados em quantidades consideráveis. ${ }^{215,216}$

Algumas algas produzem grandes quantidades de lipídeos com ácidos graxos poli-insaturados de cadeias longas (PUFAs) que, embora possam ser transformados em ésteres, também são inadequados para a utilização como biodiesel, devido à presença de inúmeras posições bis-alílicas que apresentam forte tendência a sofrer oxidação, o que resulta em uma maior instabilidade do biodiesel durante períodos longos de estocagem. Exemplo disso é a alga verde Parietochloris incise ${ }^{217}$ cujo óleo contém de 34 a $42 \%$ de PUFAs como o ácido araquidônico $\left(\mathrm{C}_{20: 4}\right)$, ácido eicosapentanoico - EPA $\left(\mathrm{C}_{20: 5}\right)$ e o ácido docosa-hexanoico - DHA $\left(\mathrm{C}_{22: 6}\right)$. Estes três ácidos graxos são os principais componentes da Phacodactylum tricornutum e da Crypthecodinium cohnii ${ }^{218}$ apresentando cerca de 30 e de 30 a $50 \%$ do conteúdo total destes ácidos graxos, respectivamente.

Em contraste com outras plantas superiores, a variação da composição química em ácidos graxos nas microalgas é muito grande, dentro e entre os grupos taxonômicos. Conforme já foi ressaltado, a escolha certa da matéria-prima que será usada na produção do biodiesel dependerá, em primeira instância, da composição química desse óleo. Neste sentido, apesar da produção de PUFAs por muitas algas $^{216}$ como $\mathrm{C}_{20: 4} ; \mathrm{C}_{20: 5} ; \mathrm{C}_{22: 5} ; \mathrm{C}_{22: 6}$ entre outros, ${ }^{215,216}$ os ácidos graxos mais comumente encontrados são os de 16 e 18 carbonos com cadeias saturadas ou com diferentes padrões de mono-insaturação, $\mathrm{C}_{16: 0} ; \mathrm{C}_{16: 1} ; \mathrm{C}_{18: 1} \cdot{ }^{216,219,220}$

Além de altos percentuais de óleo em relação à massa da célula seca poderem ser obtidos a partir de algumas algas, existe a possibilidade de algumas espécies produzirem óleos vegetais onde a ausência de PUFAs pode ser comprovada, possibilitando a produção de um biodiesel de alta qualidade. Conseguindo essa viabilidade técnica, a viabilidade econômica será fruto das altas produtividades, tanto do óleo desejado quanto da biomassa remanescente, após a extração do óleo e que pode ser empregada como outra fonte de bioenergia.

Os triglicerídeos produzidos por essas algas podem, ainda, ter a sua composição química modificada em teores de ácidos graxos, de acordo com fatores como as condições de crescimento fototrópicas (intensidade de luz, temperatura) e/ou heterotrópicas ${ }^{216,221}$ (suplementação ou restrição de determinadas substâncias químicas que influenciam o metabolismo, além de aumentar o volume de óleo produzido). O cultivo de microalgas com dióxido de carbono e com bicarbonato de sódio é um exemplo disso. ${ }^{221} \mathrm{O}$ crescimento da
Chlorella protothecoides em fermentadores, empregando a técnica de controle metabólico através do cultivo heterotrópico, com a adição de hidrolisado de milho em pó como fonte de glucose, resultou na produção e acúmulo de 55,2\% de lipídeos de composição química considerada excelente para ser usado como matéria-prima na produção de biodiesel. Os principais componentes do óleo formado foram os ácidos oleico $60,8 \%$ e o linoleico $17,3 \%$.

Uma outra linhagem de Chlorella, não divulgada por questões de proteção comercial, tem sido cultivada pela empresa americana PetroSun. Em trabalho de colaboração com essa empresa, o nosso grupo de pesquisa tem estudado em detalhes a composição química do óleo produzido que, em função da ausência total de PUFAs e sendo majoritariamente constituído de ácido linoleico $\left(\mathrm{C}_{18: 2}, 50,5 \%\right)$ e oleico $\left(\mathrm{C}_{18: 1}, 21,5 \%\right)$, se mostrou adequado à produção de um biodiesel de alta qualidade. ${ }^{222} \mathrm{O}$ biodiesel metílico produzido utilizando $\mathrm{CuCl}_{2}$ como catalisador apresentou índice de iodo de 115 e foi usado para reconfirmar a composição química em termos de ácidos graxos por CG/MS. ${ }^{81}$

Neste sentido, o uso de ferramentas biotecnologicas que ajudem a modificar a composição e os teores dos ácidos graxos produzidos por uma determinada planta, melhorando a sua aplicabilidade e desempenho, deverá ser uma das linhas de pesquisa e desenvolvimento que poderá ajudar a facilitar um uso mais extensivo e economicamente viável do biodiesel. ${ }^{33,197,198}$

Outras substâncias químicas na composição dos óleos vegetais

O uso de óleos vegetais não alimentícios tem sido proposto recentemente como forma de aliviar o debate de alimentos versus biocombustíveis. Exemplos são o uso da mamona (Ricinnus communis), do pinhão manso (Jatropha curcas), da karanja (Pongamia pinnata), dentre outras. Essas plantas são tóxicas devido à presença de compostos como a ricina, uma toxialbumina letal, e o alcaloide ricinina, além de um polissacarídeo proteico alergênico presentes no óleo de mamona, ${ }^{223-226}$ já a curcina e ésteres forbol são compostos tóxicos presentes no pinhão manso. ${ }^{227}$ A karanja (Pongamia pinnata) por sua vez, contém flavonas, furanoflavonas, furanoflavonois, avenasterol, cromenoflavonas e furanodicetonas que tornam o seu óleo não comestível. ${ }^{60}$

Outros óleos contêm substâncias particulares que podem ser benéficas ao biodiesel como, por exemplo, a vitamina E no caso da $\operatorname{soja}^{228}$ ou sesamol e lignanas como a sesamina e a sesamolina no caso do gergelim, ${ }^{61,203}$ as quais jogam um papel importante na estabilidade oxidativa e na atividade antioxidante desses óleos. Pouca atenção tem sido dispensada à permanência no biodiesel dessas substâncias, sejam tóxicas ou não. Além disso, nesses óleos podem ser encontradas diversas substâncias como esterois e esterol ésteres. No caso do biodiesel de canola, por exemplo, têm sido encontrados o $ß$-sitoesterol, brassicasterol, campesterol, stigmasterol e o 5-avenasterol. ${ }^{229}$ Entretanto, pouco se discute sobre a influência destas substâncias em sua composição. Neste caso, abre-se uma oportunidade de estudo e pesquisa que venha a analisar as consequências (se houver) no motor e no sistema de injeção durante a queima de substâncias não usuais.

Diferentes tipos de óleos são formados por diferentes tipos de ácidos graxos, em relação ao comprimento das cadeias hidrocarbônicas, ao grau de insaturação ou à presença de outras funções químicas ${ }^{199,230}$ como é o caso do óleo de mamona (Ricinus communis) que é constiuído por aproximadamente $90 \%$ de triglicerídeo do ácido ricinoleico, um ácido graxo monoinsaturado que contém um grupo hidroxílico ligado ao carbono 12 . Os $10 \%$ restantes são triglicerídeos de ácidos graxos não hidroxilados, principalmente oleico e linoleico..$^{231}$

Alguns autores ${ }^{231,232}$ descrevem que o óleo de mamona apresenta vantagens sobre outros óleos na reação de transesterificação devido 
à maior solubilidade do ácido ricinoleico no metanol ou etanol,,$^{231,232}$ o que possibilita realizar a reação à temperatura ambiente.

Porém, a presença do grupamento hidroxila é responsável por uma série de desvantagens para o uso dos ésteres metílicos ou etílicos do ácido ricinoleico como biodiesel, dentre as quais podemos citar a maior dificuldade de remoção da água que permanece dissolvida devido à formação de pontes de hidrogênio com o grupamento hidroxila presente no ricinoleato. Em escala laboratorial, esse fato pode não ter importância relevante, porém na produção industrial representará custos bem maiores de processamento, pois haverá maior consumo energético em relação à secagem de outro tipo de biodiesel não hidroxilado, uma vez que o volume de água dissolvida, no caso da mamona, pode ser até 5 vezes maior do que no biodiesel de soja ou outro tipo de biodiesel com cadeias essencialmente hidrocarbônicas.

Outra desvantagem importante diz respeito às propriedades físicoquímicas atípicas apresentadas pelo biodiesel de mamona. Uma delas é o baixo índice de cetano, ao redor de 38, contra o limite mínimo de 52 nas especificações de qualidade. ${ }^{4-8}$

A densidade e a viscosidade do biodiesel puro (B100) de mamona não atendem os requerimentos de qualidade estabelecidos, em função do alto conteúdo do hidroxiácido. Essas duas propriedades apresentam valores bem acima dos desejados, $0,928 \mathrm{~g} / \mathrm{cm}^{3}$ para a densidade a $15{ }^{\circ} \mathrm{C}$, contra $0,860-0,900 \mathrm{~g} / \mathrm{cm}^{3}$ dos limites das especificações ${ }^{8} \mathrm{e}$ $13,82 \mathrm{~mm}^{2} / \mathrm{s}$ para a viscosidade a $40{ }^{\circ} \mathrm{C}$, contra os limites de 3,5 a $5,0 \mathrm{~mm}^{2} / \mathrm{s}$ das especificações. ${ }^{8} \mathrm{~A}$ alta viscosidade, neste caso, mesmo após a transesterificação do óleo pode reduzir a atomização do combustível causando uma maior formação de depósitos no sistema de injeção, além de dificultar o trabalho do sistema de bombeamento do combustível.

Em trabalhos realizados por nosso grupo de pesquisa, verificou-se que, quando $80 \%$ do volume de biodiesel de mamona foi destilado sob vácuo $(2,8 \mathrm{~mm} \mathrm{Hg})$ ocorreu um decréscimo da viscosidade de 13,82 para $11,73 \mathrm{~mm}^{2} / \mathrm{s}$, em função da mudança na composição química, diminuindo o teor dos derivados ricinoleicos, já que os ésteres não hidroxilados destilam primeiro entre 145 e $168^{\circ} \mathrm{C}$, enquanto o éster com hidroxila o faz a $217^{\circ} \mathrm{C} / 2,8 \mathrm{~mm} \mathrm{Hg}$.

Essa viscosidade está muito distante do limite máximo de 6,0 $\mathrm{mm}^{2} / \mathrm{s}$ da especificação EN 14214 ou ANP 07/2008 e mais ainda daquela encontrada para os ésteres etílicos de soja $\left(4,48 \mathrm{~mm}^{2} / \mathrm{s}\right)$ obtidos usando o mesmo procedimento empregado para a obtenção do biodiesel mamona, com o $\mathrm{CuCl}_{2}$ como catalisador ${ }^{81}$ (Tabela 1).

Tabela 1. Viscosidades dos óleos e dos biodieseis de soja e de mamona

\begin{tabular}{cccc}
\hline \multicolumn{4}{c}{$v\left(40{ }^{\circ} \mathrm{C}\right) \mathrm{mm}^{2} / \mathrm{s}$} \\
\hline $\begin{array}{c}\text { Óleo de } \\
\text { soja }\end{array}$ & $\begin{array}{c}\text { Óleo de } \\
\text { mamona }\end{array}$ & $\begin{array}{c}\text { Biodiesel etílico } \\
\text { de soja }\end{array}$ & $\begin{array}{c}\text { Biodiesel etílico } \\
\text { de mamona }\end{array}$ \\
\hline 32,7 & 200,1 & 4,48 & 11,736 \\
\hline
\end{tabular}

A variação da densidade após destilação do biodiesel de mamona, conforme descrito aqui, foi muito pequena, indo de 0,920 para $0,918 \mathrm{~g} / \mathrm{cm}^{3}$, contra $0,874 \mathrm{~g} / \mathrm{cm}^{3}\left(\mathrm{~d}_{15}{ }_{\mathrm{C}}^{\circ}\right)$ para o biodiesel equivalente de soja.

Com base nestas observações, o nosso grupo de pesquisa tem estudado a correção dos parâmetros físico-químicos do biodiesel de mamona, de forma que os mesmos atendam qualquer uma das especificações de qualidade..$^{4-8} \mathrm{~A}$ adequação dos parâmetros citados foi conseguida através da mistura do biodiesel de mamona com o biodiesel de soja, nas proporções descritas na Tabela 2 .

Chegou-se à conclusão que produzindo uma mistura de $30 \%$ de biodiesel de mamona (destilado) e 70\% de biodiesel de soja (M30),
Tabela 2. Dados físico-químicos de misturas de biodiesel etílico de soja e biodiesel de mamona

\begin{tabular}{lccc}
\hline BES:BEM & $\begin{array}{c}v\left(40{ }^{\circ} \mathrm{C}\right) \\
\mathrm{mm}^{2} / \mathrm{s}\end{array}$ & $\begin{array}{c}\mathrm{d}_{15}{ }^{\circ} \mathrm{C} \\
\mathrm{g} / \mathrm{cm} 3\end{array}$ & $\begin{array}{c}\text { Índice de Iodo } \\
\mathrm{g} \mathrm{I}_{2} / 100 \mathrm{~g} \text { amostra }\end{array}$ \\
\hline $100: 0$ & 4,084 & 0,874 & 121 \\
$95: 05$ & 4,377 & 0,881 & 114 \\
$90: 10$ & 4,448 & - & 111 \\
$70: 30$ & 5,144 & 0,888 & 95 \\
$50: 50$ & 6,403 & - & 90 \\
$0: 100$ & 11,736 & 0,918 & 72 \\
\hline
\end{tabular}

a mistura se enquadrava tranquilamente dentro dos limites das especificações do B100 para a viscosidade $\left(\mathrm{M} 30=5,144 \mathrm{~mm}^{2} / \mathrm{s}\right)$, a densidade $\left(\mathrm{M} 30=0,888 \mathrm{~g} / \mathrm{cm}^{3}\right)$ e ainda possibilita a correção do índice de iodo do biodiesel de soja que apresenta muitas vezes um valor muito próximo ao limite máximo $120 \mathrm{~g} \mathrm{I} / 100 \mathrm{~g}$ de amostra. No caso do M30 produzido pelo nosso grupo, o índice de iodo observado foi de $95,3 \mathrm{~g} \mathrm{I}_{2} / 100 \mathrm{~g}$ de amostra.

Mesmo que o sucesso da correção dos parâmetros físico-químicos citados do biodiesel de mamona possa significar uma viabilidade técnica, os resultados não sanam as dificuldades econômicas da sua produção, nem as diferenças de custo em relação à produção de biodiesel a partir de outras matérias-primas.

Da mesma forma, para tornar economicamente viável o uso de plantas como a Jatropha e a mamona deve-se encarar também o desafio de estabelecer, com base científica e confiável, processos de custos reduzidos para a desintoxicação das tortas (farelos) através da remoção ou transformação das substâncias químicas tóxicas que nelas permanecem após a extração do óleo e que, portanto, não podem ser usadas para alimentação animal. ${ }^{233-235}$

\section{CONCLUSÃO}

A procura por "novas matérias-primas" a serem utilizadas na produção do biodiesel tem esbarrado no fato de que muitos óleos ou gorduras vegetais e animais não possuem composição adequada para permitir que o produto da sua transesterificação se enquadre nas especificações de qualidade exigidas para ser usado como combustível. Um exemplo disto é a mamona (Ricinus communis), que produz um óleo atípico. Estudos realizados por nosso grupo de pesquisa mostraram ser possível a redução da viscosidade e da densidade do óleo não apenas através do processo de transesterificação, mas ainda pela destilação do biodiesel. O biodiesel etílico de mamona destilado foi misturado em várias proporções volumétricas ao biodiesel etílico de soja, de modo que as propriedades físico-químicas como densidade, viscosidade e índice de iodo das misturas se enquadrassem nas normas EN 14214 ou ANP 07/2008. Verificou-se que para as misturas entre estes biodieseis, a faixa de 70 a $95 \%$ de biodiesel etílico de soja é a mais indicada para atender às especificações de viscosidade, densidade e índice de iodo.

Em termos de processo, a revisão da literatura apresentada neste artigo, mostra que a busca por alternativas à transesterificação alcalina convencional com alcoolatos tem sido intensivamente perseguida. Os resultados publicados mostram grande potencial de melhoria sobre fatores específicos, baseados em vantagens pontuais. Porém, nenhuma das alternativas já publicadas tem se mostrado capaz de substituir o processo atualmente empregado na indústria. Isto pode ser afirmado porque, ao se analisar os processos completos usando os desenvolvimentos pontuais publicados, se observam desvantagens técnicas que se traduzem em inviabilidade (desvantagem) econômica. 
Em todos os casos, as vantagens apresentadas nas publicações estão sempre acompanhadas das mais diversas limitações.

Assim podemos citar como exemplos, a realização da transesterificação em condições supercríticas que elimina a necessidade de catalisador, enquanto o uso de catalisadores heterogêneos facilita a recuperação e reutilização dos mesmos. Ambos os processos deixam os produtos mais fáceis de serem purificados. Entretanto, apresentam desvantagem quanto ao elevado consumo energético durante sua aplicação, pois requerem condições de alta temperatura e pressão.

Além disso, no caso dos catalisadores enzimáticos, não há formação de sabões, a purificação do biodiesel e da glicerina é facilitada, pois não são contaminados com produtos químicos ácidos ou alcalinos, mas apresentam as desvantagens de longos tempos reacionais e na maioria das vezes transformações parciais, além dos elevados custos das enzimas.

Já as aplicações de ultrassom ou micro-ondas sugeridas em alguns trabalhos, embora possam acelerar a reação de transesterificação, não contribuem significativamente ao processo como um todo, pois não aceleram a obtenção do biodiesel, já que a maior demora está no refino, lavagem, secagem e outras operações necessárias. Os equipamentos de ultrassom e micro-ondas ainda aumentam o consumo energético e também o custo de investimento.

Portanto, estudos futuros deverão se basear na solução de problemas realmente encontrados pela indústria mais do que meramente no desenvolvimento pontual e com direcionamento essencialmente acadêmico. Essas soluções deverão permitir, por exemplo, o desenvolvimento e a aplicação de novos catalisadores que se aproximem daquilo que pode ser considerado o "catalisador ideal", porém integradas com o desenvolvimento de processos alternativos completos visando sua eficiência global.

No curto prazo, ainda há muito espaço para inovações que permitam melhorar a aplicação do processo "clássico" com os alcoolatos metílicos ou etílicos de sódio ou potássio em ciclo fechado, o que resulta na eliminação da formação de qualquer tipo de efluente líquido ou sólido (promovendo a remediação durante o processo produtivo). Além disso, a glicerina deve ser produzida com qualidade suficiente para permitir a sua comercialização, como glicerina $86 \%$ (loira), glicerina branca bidestilada $(99,5 \%)$ ou ainda glicerina farmacêutica $(99,9 \%)$. A água e o álcool (seja ele metanol ou etanol) terão de ser totalmente recuperados e reutilizados no ciclo produtivo e o catalisador derivatizado para a formação de produtos químicos úteis como, por exemplo, sulfato ácido de potássio, sulfato de potássio ou cloreto de potássio que podem ser usados em formulações de fertilizantes ou ainda na produção do catalisador $\left(\mathrm{KCl} \rightarrow \mathrm{K}^{0} \rightarrow \mathrm{CH}_{3} \mathrm{OK}\right.$ ou $\mathrm{KCl} \rightarrow$ $\mathrm{KOH})$. No caso do processo etílico, o catalisador (etilato de sódio) poderia ser "transformado" no citrato de sódio que tem valor comercial nas indústrias alimentícia, de refrigerantes e outras.

Acreditamos também ser necessário o desenvolvimento de novas enzimas "coengenheiradas" e imobilizadas, desenhadas para cumprir o rol da transesterificação em processos laboratoriais e industriais, porém, com maior eficiência do que aquelas já conhecidas e que atualmente não permitem a produção eficiente e competitiva em escala industrial.

Outras alternativas são a prospecção de novos organismos de ocorrência natural que poderiam produzir lipídeos diretamente, na forma de mono-ésteres alquílicos de ácidos graxos de cadeia longa e álcoois de cadeia curta ( $n=1,2$ ou 3 ) ou pesquisar a coengenharia de novos organismos para serem usados como "máquinas produtivas" ou "biorrefinarias" reais, que possam produzir o biodiesel diretamente pela modificação do seu metabolismo (heterotropismo) ou do seu genoma. Assim, podemos prever uma próxima geração de plantas e micro-organismos energéticos que conterão os códigos genéticos e as enzimas necessárias para que a produção de biodiesel ocorra in vivo ou in planta.

A maior barreira a ser ultrapassada na atualidade, de modo a desvencilhar o dilema entre a produção acadêmica e a produção industrial, trata-se de acordar os cientistas para a pesquisa fundalmentalmente aplicada na área de biocombustíveis, principalmente quanto à produção de biodiesel. Embora os desenvolvimentos científicos e tecnológicos futuros para viabilizar economicamente a produção do biodiesel sejam um grande desafio, os avanços necessários para atingir as metas propostas parecem, no entanto, ser realizáveis.

\section{REFERÊNCIAS}

1.Energy Information Administration; International Energy Outlook 2007, US Department of Energy, http://www.eia.doe.gov/oiaf/archive/aeo07/ pdf/0383(2007).pdf, acessada em Março 2007.

2. Kintish, E.; Science Now 2007.

3. Herrera, S.; Nat. Biotechnol. 2006, 24, 755.

4. Biodiesel Standard; ASTM D6751, USA, 2002.

5. Biodiesel Standard; ASTM PS 121, USA, 1999.

6. Biodiesel Standard; EN 14214, European Standard Organization, 2003.

7. Biodiesel Standard; DIN V51606, Germany, 1994.

8. Biodiesel Standard; Resolução ANP $n^{\circ}$ 7, Diário Oficinal da União, Brasil, 2008, 20/3/2008.

9. Ma, F.; Hanna, M. A.; Bioresour. Technol. 1999, 70, 1.

10. Canacki, M.; Gerpen, J. V.; Trans ASAE 2001, 44, 1429.

11. Lotero, E.; Lui, Y.; Lopez, D. E.; Swwannakarn, K.; Bruce, D. A.; Goodwin, J. G. J.; Ind. Eng. Chem. Res. 2005, 44, 5353.

12. Canacki, M.; Bioresour. Technol. 2007, 98, 183.

13. Narassimharao, K.; Lee, A.; Wilson, K.; J. of Biobased Materials and Bioenergy 2007, 1, 19.

14. Fukuda, H.; Kondo, A.; Noda, H.; J. Biosci. Bioeng. 2001, 92, 405.

15. Schuchardt, U.; Sercheli, R.; Vargas, R. M.; J. Braz. Chem. Soc. 1998, 9, 199.

16. Chavanne, C. G.; pat. BE 422,877, Belgica 1938.

17. Chavanne, C. G.; Bull. Soc. Chim. 1943, 10, 52.

18. Wang, R.; Taiyang-neng Xuebao 1988, 9, 434. (CA 1989, 111, 26233).

19. Feuge, R. O.; Gros, A. T.; J. Am. Oil Chem. Soc. 1949, 26, 97.

20. Norris, F. A.; Mattil, K. F.; Oil and Soap 1946, 23, 289.

21. Trent, W. R.; US pat. 2,383,632 1942.

22. Donald, P.; Sprules, F. J.; US Pat. 2,543,421 1951

23. Root, F .B.; US Pat. 2,559,466 1951.

24. Kent, S. M.; US Pat. 2,562,218 1951.

25. Chang, C. C.; Wan, S.-W.; Ind. Eng.Chem. 1947, 39, 1543. (CA 1948, 42:1037h).

26. Cheng, F.-W.; Chem. Metall. Eng. 1945, 52, 99.

27. Egloff, G.; Morrell, J. C.; Ind. Eng. Chem. 1932, 1426.

28. Parente, E. J. S.; BR Pat. PI 8007957, Brasil, 1980.

29. Vicente, G.; Martínez, M.; Aracil, J.; Bioresour. Technol. 2004, 92, 297.

30. Liu, Y.; Lotero, E.; Goodwin Jr., J. G.; J. Mol. Catal. A: Chem. 2006, $245,132$.

31. Lopez, D. E.; Goodwin Jr., J. G.; Bruce, D. A.; Lotero, E.; Appl. Catal. A: Gen 2005, 295, 97.

32. Kinast, J. A.; Tyson, K. S.; Final report NREL, Golden, CO, 2003, vol. 1, p. 53.

33. Hass, M. J.; Mc. Aloon, A. J.; Yee, W. J.; Foglia, T. A.; Bioresour. Technol. 2006, 97, 671.

34. Ramadhas, A. S.; Jayaraj, S.; Muraleedharan, C.; Fuel 2005, 84, 335.

35. Veljkovic, V. B.; Lakicevic, S. H.; Stamenkovic, O. S.; Todorovic, Z. B.; Lazic, M. L.; Fuel 2006, 85, 2671. 
36. Clements, L. D.; US pat. $20060224006 A 12005$.

37. Almeida, N. H.; BR Pat. PI0104107-0 2001.

38. Samios, D.; Pedrotti, F.; Nicolau, A.; Reiznautt, Q. B.; Matini, D. D.; Dalcin, F. M. A.; Fuel Process. Technol. (2009), doi:10.1016/j. fuproc.2008.12.011.

39. Schwab, A. W.; Bagby, M. O.; Freedman, B.; Fuel 1987, 66, 1372.

40. Freedman, B.; Butterfield, R. O.; Pryde, E. H.; J. Am. Oil Chem. Soc. 1986, 63, 1375.

41. Balat, M.; Balat, H.; Energy conversion and Management 2008, 49, 2727.

42. Lotero, E.; Goodwin Jr., J. G.; Bruce, D. A.; Suwannakarn, K.; Lin, Y.; Lopez, D. E.; Catal. 2006, 19, 41.

43. Berrios, M.; Skelton, R. L.; Chem. Eng. J. 2008, 144, 459.

44. Granados, M. L.; Poves, M. D. Z.; Alonso, D. M.; Mariscal, R.; Galisteo, F. C.; Moreno- Tost, R.; Santamaría, J.; Fierro, J. L. G.; Appl Catal B: Environ. 2007, 73, 317.

45. Ngamcharussrivichai, C.; Totorat, P.; Bunyakiat, K.; Appl Catal. A: General 2008, 341, 77.

46. Dabdoub, M. J.; Dabdoub, V. M. B.; Hurtado, G. R.; Batista, A. C. F.; Bortoleto, D. A.; BR Pat. PI0502795-0 2005.

47. Cooke, B. S., Abrams, S.; Bertram, B.; US pat. 0509959P 2003.

48. Chongkhong, S.; Tonguri, C.; Chetpattananondh, P.; Renewable Energy 2009, 34, 1059.

49. Zheng, S.; Kates, M.; Dube, M. A.; McLean, D. D.; Biomass and Bioenergy 2006, 30, 267.

50. Di Serio, M.; Tesser, R.; Dimiccoli, M.; Cammarota, F.; Nastasi, M.; Santanecesaria, E.; J Mol Catal A: Chem. 2005, 1-2, 111.

51. Takagaki, A.; Toda, M.; Okamura, M.; Kondo, J. N.; Hayashi, S.; Domen, K.; Hara, M.; Catal. Today 2006, 116, 157.

52. Caetano, C. S.; Fonseca, I. M.; Ramos, A. M.; Vital, J.; Castanheiro, J. E.; Catal. Commun. 2008, 9, 1996.

53. Perin, G.; Alvaro, G.; Westphal, E.; Viana, L. H.; Jacob, R. G.; Lenardao, E. J.; D’Oca, M. G. M.; Fuel 2008, 87, 2838.

54. Azcan, N.; Danisman, A.; Fuel 2008, 87, 1781.

55. Lima, J. R. O.; da Silva, R. B.; de Moura, E. M.; de Moura, C. V. R.; Fuel 2008, 87, 1718.

56. Lin, C-Y.; Li, R-J.; Fuel Process Technol. 2009, 90, 130.

57. Shi, H.; Bao, Z.; Bioresour. Technol. 2008, 99, 9025.

58. Arzamendi, E.; Arguinarena, E.; Campo, I.; Zabala, S.; Catal. Today 2008, 133, 305.

59. Alamu, O. J.; Waheed, M. A.; Jekaynfa, S. O.; Fuel 2008, 87, 1529.

60. Sharma, Y. C.; Singh, B.; Fuel 2008, 87, 1740.

61. Saydut, A.; Duz, M. Z.; Kaya, C.; Kadafar, A. B.; Hamamci, C.; Bioresour. Technol. 2008, 99, 6656.

62. Lu, H.; Liu, Y.; Zhou, H.; Yang, Y.; Chen, M.; Liang, B.; Computers Chem. Eng. 2008, XX, 000.

63. Berchamans, H. J.; Hirata, S.; Biosour. Technol. 2008, 99, 1716.

64. Sahoo, P. K.; Das, L. M.; Babu, M. K. G.; Naik, S. N.; Fuel 2007, 86, 448.

65. Hernado, J.; Leton, P.; Matia, M. P.; Navella, J. L.; Alvarez-Builla, J.; Fuel 2006, 86, 1641.

66. Saifuddin, N.; Chua, K. H.; Malays J. Chem. 2004, 6, 77.

67. Azcan, N.; Danisman, A.; Fuel 2007, 86, 2639.

68. Freedman, B.; Butterfield, R. O.; Pryde, E. H.; J. Am. Oil. Chem. Soc. 1986, 63, 1375.

69. Kucek, K. T.; Aparecida, F. M.; Oliveira, C.; Wilhelm, H. M.; Ramos, L. P.; J. Am. Oil Chem. Soc. 2007, 84, 385.

70. Zagonel, G. F.; Ramos, L. P.; Sci. Technol. J. 2003, 1, 35.

71. Domingos, A. K.; Saad, E. B.; Wilhelm, H. M.; Ramos, L. P.; Proceedings of the XI Congreso Latinoamericano de Grasas y Aceites, Buenos Aires, 2003, p. 318.

72. Cordeiro, C. S.; Dissertação de Mestrado, Universidade Federal do Paraná, Brasil, 2003.
73. Saka, S.; Kusdiana, D.; Fuel 2001, 80, 225.

74. Kusdiana, D.; Saka, S.; Fuel 2001, 80, 693.

75. Han, H. W.; Cao, W. L.; Zhang, J. C.; Process. Biochem. 2005, 40, 3148.

76. Cao, W. L.; Han, H. W.; Zhang, J. C.; Fuel 2005, 84, 347.

77. Dermibas, A.; Energy Conv. Manage. 2007, 48, 937.

78. Kouzu, M.; Yamanaka, S.; Kasuno, T.; Tajika, M.; Aihara, Y.; Sugimoto, Y.; Hidaka, J.; J. Jp Petrol Inst. 2007, 50, 79.

79. Yin, J-Z.; Xiao, M.; Song, J-B.; Energy Convers Manage. 2008, 49, 908.

80. Hawash, S.; Kamal, N.; Zahas, F.; Kanawi, O.; El- Dinawi, G.; Fuel 2009, 88, 579.

81. Dabdoub, M. J.; Dabdoub, V. B.; Bortoleto, D. A.; Rodrigues, H. S.; Rampin, M. A.; BR Pat. PI0702149-6 2007.

82. Dabdoub, M. J.; Dabdoub, V. B.; Bortoleto, D. A.; Rodrigues, H. S.; Rampin, M. A.; BR Pat. PI0702448-7 2007.

83. Ferreira, D. A. C.; Meneghetti, M. R.; Meneghetti, S. M. P.; Wolf, S. R.; Appl. Catal. A: Gen 2007, 317, 58.

84. Xie, W.; Li, H.; J. Mol. Catal. A: Chem. 2006, 255, 1.

85. Xie, W.; Peng, H.; Chen, L.; Appl. Catal. A: Gen. 2006, 300, 67.

86. Kouzu, M.; Kasuno, T.; Tajika, M.; Sugimoto, Y.; Yamanaka, S.; Hidaka, J.; Fuel 2008, 87, 2798.

87. Van Gerpen, J.; Fuel Process. Technol. 2005, 86, 1097.

88. Dermibas, A.; Science 2007, 33, 1.

89. Cantrell, D. G.; Gillie, L. J.; Lee, A. F.; Wilson, K.; Appl. Catal. A: Gen 2005, 287, 183.

90. Bournay, L.; Casanave, D.; Delfort, B.; Hillion, G.; Chodorge, J. A.; Catal. Today 2005, 106, 190.

91. Hillion, G.; Bournay, L.; Delfort, B. ; Pat. FR2890656 2007.

92. Garcia, M. C.; Teixeira, S.; Marciniuk, L. L.; Schuchardt, U.; Bioresour. Technol. 2008, 99, 6608.

93. Antunes, O. A. C.; Quim. Nova 2005, 28 Suplemento, S64.

94. Shibasaki-Kitikawa, N.; Honda, H.; Kuribayashi, H.; Toda, T.; Fukumura, T.; Yonemoto, T.; Bioresour. Technol. 2007, 98, 416.

95. López, D. E.; Goodwin Jr, J. G.; Bruce, D. A.; J. Cat. 2007, 245, 381.

96. Guerreiro, L.; Castanheira, J. E.; Fonseca, I. M.; Martin-Andrada, R. M.; Ramos, A. M.; Vital, J.; Catal. Today 2006, 118, 166.

97. Dube, M. A.; Tremblay, A. Y.; Liu, J.; Bioresour. Technol. 2007, 98, 639.

98. Xie, W.; Huang, X.; Catal. Lett. 2006, 107, 1.

99. Liu, X.; He, H.; Wang, Y.; Zhu, S.; Catal. Commun. 2007, 8, 1107.

100. Yang, Z.; Xie, W.; Fuel Process. Technol. 2007, 88, 631.

101. Kim, H. J.; Kang, B. S.; Park, Y. M.; Kim, D. K.; Lee, J. S.; Lee, K. Y.; Catal. Today 2004, 93-95, 315.

102. Suppes, G. J.; Dasan, M. A.; Doskocil, E. J.; Mankidy, P. J.; Golf, M. J.; Catal. A: Gen. 2004, 257, 213.

103. Xie, W.; Huang, X.; Li,H.; Bioresour. Technol. 2007, 98, 936.

104. Ranganathan, S. V.; Narasimhan, S. L.; Muthukumar, K.; Bioresour. Technol. 2008, 99, 3975.

105. Shieh, C. J.; Liao, H. F.; Lee, C. C.; Bioresour. Technol. 2003, 88, 103.

106. Furuta, S.; Matsuhashi, H.; Arata, K.; Catal. Commun. 2004, 5, 721.

107. López, D. E.; Swwannakarn, K.; Bruce, D. A.; Goodwin Jr., J. G.; J. Catal. 2007, 247, 43.

108. Rao, K. N.; Sridhar, A.; Lee, A. F.; Tavener, S. J.; Young, N. A.; Wilson, K.; Green Chem. 2006, 8, 790.

109. Kiss, A. A.; Dimian, C. A.; Rothenberg, G.; Adv. Synth. Catal. 2006, $348,75$.

110. dos Reis, S. C. M.; Lachter, E. R.; Nascimento, R. S. V.; Rodrigues Jr., J. A.; Reid, M. G.; J. Am. Oil Chem. Soc. 2005, 82, 661.

111. Mo, X.; López, D. E.; Swwannakarn, K.; Liu, Y.; Lotero, E.; Goodwin Jr., J. G.; Lu, C.; J. Catal. 2008, 254, 332.

112. Ni, J.; Meunier, F. C.; Appl. Catal. A: Gen. 2007, 333, 122. 
113. Liu, Y.; Lotero, E.; Goodwin Jr., J. G.; J. Catal. 2006, 243, 221.

114. Liu, Y.; Lotero, E.; Goodwin Jr, J. G.; J. Catal. 2006, 242, 278.

115. Nijhuis, T. A.; Beers, A. E. W.; Kapteijn, F.; Moulijn, J. A.; Chem. Eng. Sci. 2002, 57, 1627

116. Carmo Jr., A. C.; Lopes de Souza, K. C.; da Costa, C. E. F.; Longo, E.; Zamian, J. R.; Fuel 2009, 88, 461.

117. Hamad, B.; Lopes de Souza, K. C.; Sapaly, G.; Carneiro Rocha, M. G.; Pries de Oliveira, P. G.; Gonzalez, W. A.; Andrade Sales, E.; Essayem, N.; Catal. Commun. 2008, 10, 92.

118. Liu, R.; Wang, X.; Zhao, X.; Feng, P.; Carbon 2008, 46, 1664. Além das refs. 37, 38, 42-50, 163-165.

119. Mbaraka, I. K.; Radu, D. R.; Lin, V. S-Y.; Shanks, B. H.; J. Catal. 2003, 219, 329.

120. Mbaraka, I. K.; Shanks, B. H.; J. Am. Oil Chem. Soc. 2006, 83, 79.

121. Mbaraka, I. K.; Mc Guire, K. J.; Shanks, B. H.; Ind. Eng. Chem. Res. 2006, 45, 3022

122. Jackson, M. A.; Mbaraka, I. K.; Shanks, B. H.; Appl. Catal. A: Gen. 2006, 310, 48

123. Kansedo, J.; Lee, K. T.; Bathia, S.; Biomass and Bioenergy 2008, I-6, 000 .

124. Jitputti, J.; Kitiyan, B.; Rangsunvigit, P.; Bunyakiat, K.; Attanatho, L.; Jenvanitpan, P.; Chem. Eng. J. 2006, 116, 61.

125. Kiss, A. A.; Omota, F.; Dimian, A. C.; Rothenberg, G.; Topics Catal 2006, 40, 141.

126. Lopéz, D. E.; Goodwin Jr., J. G.; Bruce, D. A.; Furuta, S.; Appl. Catal. A: Gen. 2008, 339, 76.

127. McNeff, C. V.; McNeff, L. C.; Yang, B.; Nowlan, D. T.; Rasmussen, M.; Gyberg, A. E.; Krohn, B. J.; Fedie, R. L.; Hoye, T. R.; Appl. Catal. A: Gen. 2008, 343, 39.

128. Ramu, S.; Lingaiah, N.; Prabhavathi Devi, B. L. A.; Prasad, R. B. N.; Suryanarayana, I.; Sai Prasad, P. S.; Appl. Catal. A: Gen. 2004, 276, 163.

129. Ishihara, K.; Nakayama, M.; Ohara, S.; Yamoto, H.; Tetrahedron 2002. $58,8179$.

130. Omota, F.; Dimian, A. C.; Bliek, A.; Chem. Eng. Sci. 2003, 58, 3175.

131. Ginosar, D. M.; Fox, R. V.; US pat. 6,887,283 2005.

132. Takasaki, S.; pat. WO2006070661 2006.

133. Lacome, T.; Hillion, G.; Delfort, B.; Revel, R.; Leporq, S.; Paille, F.; pat. FR2855518 2004.

134. Lacome, T.; Hillion, G.; Delfort, B.; Revel, R.; Leporq, S.; Chaumonnot, A.; pat. FR285519 2004.

135. Liu, X.; Piao, X.; Wang, Y.; Zhu, S.; He, H.; Fuel 2008, 87, 1076.

136. Schuchardt, U.; Vargas, R. M.; Gelbard, G. J.; J. Mol. Catal. A: Chem. 1996, 109, 37

137. Gryglewics, S.; Bioresour. Technol. 1999, 70, 249.

138. Griglewicz, S.; Appl. Catal. A: Gen. 2000, 192, 23.

139. Radich, A.; Energy Information Administration 2006, p.1.

140. Bournay, L.; Hillion, G.; Boucot, P.; Chodorge, J.-A.; Bronner, C.; Forestiere, A.; US pat. 20040034244, 2004.

141. Bournay, L.; Hillion, G.; Boucot, P.; Chodorge, J.-A.; Bronner, C. Forestiere, A.; US pat. 6,878,837 2005.

142. Bournay, L.; Baudot, A.; US pat. 7,138,536 2006

143. Reddy, C.; Reddy, V.; Oshel, R.; Verdake, J. G.; Energy Fuels 2006, 20, 1310 .

144. Albuquerque, M. C. C.; Santamaria-Gonzales, J.; Mérida-Robles, J. M.; Moreno-Tost, R.; Rodriguéz-Castellón, E.; Jiménez-López, A.; Azevedo, D. C. S.; Cavalcante Jr, C. L.; Mairales-Torres, P.; Appl. Catal. A: Gen. 2008, 347, 162 .

145. Kawashima, A.; Matsubara, K.; Honda, K.; Bioresour. Technol. 2008 99, 3439.

146. Albuquerque, M. C. G.; Jiménez-Urbistondo, I.; Santamaría-Gonzalez, J.; Mérida-Robles, J. M.; Moreno-Tost, R.; Rodríguez-Castellón, E.; Jiménez-López, A.; Azevedo, D. C. S.; Cavalcante, Jr., C. L.; MairelesTorres, P.; Appl. Catal. A: Gen. 2008, 334, 35.
147. Dossin, T. F.; Reyners, M-F.; Berger, R. J.; Marin, G. B.; Appl. Catal. B: Environ. 2006, 67, 136.

148. Macedo, C. C. S.; Abreu, F. R.; Tavares, A. P.; Alves, M. B.; Zara, L. F.; Rubim, J. C.; Suarez, P. A. Z.; J. Braz. Chem. Soc. 2006, 17, 1291

149. Ebiura, T.; Echizen, T.; Ishikawa, A.; Murai, K.; Baba, T.; Appl. Catal. A: Gen. 2005, 238, 111.

150. Veldurthy, B.; Clasens, J. M.; Figueras, F.; J. Catal. 2005, 229, 237.

151. Ranganathan, S. V.; Narasimhan, S. L.; Muthukumar, K.; Bioresour. Technol. 2007; doi: 101016/ j. biiortech.2007.04.060.

152. Negishi, S.; Shirasawa, S.; Suzuki, J.; Murui, T.; US pat. 5,480,787 1994.

153. Hernandez-Martin, E.; Otero, C.; Bioresour. Technol. 2008, 99, 277.

154. Al-Zuhair, S.; Biofuels Bioproducts Biorefining 2007, 1, 57.

155. Al-Zuhair, S.; Fan, Y. W.; Lin, S. J.; Process Bioch. 2007, 42, 951.

156. Jegannathan, K. R.; Abang, S.; Poncelet, D.; Chan, E. S.; Ravindra, P.; Crit. Rev. Biotechnol. 2008, 28, 253.

157. Bommarius, A. S.; Riebel-Bommarius, B. R.; Biocatalysts: Fundamentals and Aplications, John Wiley \& Sons: New York, p. 266.

158. Bosley, J. A.; Peilow, A. D.; J. Am. Oil Chem. Soc. 1997, 74, 107.

159. Yadav, G. D.; Jadhav, S. R.; Microporous Mesoporous Mater. 2005, 86, 215.

160. Hurtado, C.; Dissertação de Mestrado, Universidade de São Paulo, Brasil, 2006.

161. Rampin, M. A.; Dissertação de Mestrado, Universidade de São Paulo, Brasil, 2007.

162. Antczak, S. M.; Kubiak, A.; Antczak, T.; Bielecki, S.; Renewable Energy (2009), doi: 10. 1016/j.renene.2008.11.013.

163. Shimada, Y.; Watanabe, Y.; Sugihara, A.; Tominaga, Y.; J. Mol. Catal. B: Enzym. 2002, 17, 133.

164. Xu, Y.; Du, W.; Liu, D.; Zeng, J.; Biotechnol. Lett. 2003, 25, 1239.

165. Rodrigues, R. C.; Volpato, G.; Wada, K.; Ayub, M. A. Z.; J. Am. Oil Chem. Soc. 2008, 85, 925.

166. Nelson, L. A.; Foglia, T. A.; Marmer, W. N.; J. Am. Oil Chem. Soc. 1996, 73,1191 .

167. Dossat, V.; Combes, D.; Marty, A.; Enz. Microb. Technol. 2002, 30, 90.

168. Soumanou, M. M.; Bornscheuer, U. T.; Enz. Microb. Technol. 2003, 33, 97.

169. Dizge, N.; Keskinler, B.; Biomass and Bioenergy 2008, 32, 1274.

170. Wu, W. H.; Foglia, T. A.; Marmer, W. N.; Philips, J. G.; J. Am. Oil Chem. Soc. 1999, 76, 517.

171. Akoh, C. C.; Chang, S. W.; Lee, G.-C.; Shaw, J.-F.; J. Agric. Food Chem. 2007, 55, 8995 e refs. citadas.

172. Talukder, M. M. R.; Puah, S. M.; Wu, J. C.; Won, C. J.; Chow, Y.; Biocatal. Biotrans. 2006, 24, 257.

173. Salis, A.; Pinna, M.; Monduzzi, M.; Solinas, V.; J. Biotechnol. 2005, 119, 291.

174. Du, W.; Xu, Y.-Y.; Zeng, J.; Liu, D.-H.; Biotechnol. Appl. Biochem. 2004, 40, 187.

175. Kaieda, M.; Samukawa, T.; Kondo, A.; Fukuda, H.; J. Biosci. Bioeng. 2001, 91, 12.

176. Oda, M.; Kaieda, M.; Hama, S.; Yamaji, H.; Kondo, A.; Izumoto, E.; Biochem. Eng. J. 2005, 23, 45

177. Al-Zuhair, S.; Jayaraman, K. S.; Smita, K.; Chan, W.; Biochem. Eng. J. 2006, 30, 212.

178. Shimada, Y.; Watanabe, Y.; Sugihara, A.; Noda, H.; Fukuda, H.; Tominaga, Y.; J. Am. Oil Chem. Soc. 1999, 76, 789

179. Noureddini, H.; Gao, X.; Philkana, R. S.; Bioresour. Technol. 2005, 96, 769.

180. Matsumoto, T.; Fukuda, H.; Ueda, M.; Tanaka, A.; Kondo, A.; Appl. Envir. Microb. 2002, 4517

181. Matsumoto, T.; Takahashi, S.; Kaieda, M.; Ueda, M.; Tanaka, A.; Fukuda, H.; Kondo, A.; Appl. Microbiol. Biotechnol. 2001, 57, 515. 
182. Ban, K.; Kaieda, M.; Matsumoto, T.; Kondo, A.; Fukuda, H.; Biochem. Eng. J. 2001, 8, 39.

183. Kaieda, M.; Samukawa, T.; Matsumoto, T.; Ban. K.; Kondo, A.; Shimada, Y.; Noda, H.; Nomoto, F.; Ohtsuka, K.; Izumoto, E.; Fukuda, H.; J. Biosci. Bioeng. 1999, 88, 627.

184. Hama, S.; Yamaji, H.; Fukuzumi, T.; Numata, T.; Tamalampudi, S.; Kondo, A.; Noda, H.; Fukuda, H.; Biochem. Eng. J. 2007, 34, 273.

185. Tamalampudi, S.; Talukder, M. R.; Hama, S.; Numata, T.; Kondo, A.; Fukuda, H.; Biochem. Eng. J. 2008, 39, 185.

186. Li, W.; Du, W.; Liu, D.; Process. Biochem. 2007, 42, 1481.

187. Qin, H.; Xu, Y.; Dong, W.; Chin. J. Catal. 2008, 29, 41.

188. Tamalampudi, S.; Talukder, M. R.; Hama, S.; Tamino, T.; Suzuki, Y.; Kondo, A.; Fukuda, H.; Appl. Microbiol. Biotechnol. 2007, 75, 387.

189. Himmel, M. E.; Ding, S-Y.; Johnson, D. K.; Adney, W. S.; Ninhos, M. R; Brady, J. W.; Foust, T. D.; Science 2007, 315, 804.

190. Yuan, J. S.; Tiller, K. H.; Al-Ahmad, H.; Stewart, N. R.; Stewart Jr., C. N.; Science 2008, 13, 421.

191. Mukhopadhyay, A.; Redding, A. M.; Rutherford, B.; Keasling, J. D.; Cur. Opin. Biotechnol. 2008, 19, 228.

192. Fortman, J. L.; Chhabra, S.; Mukhopadhyay, A.; Chou, H.; Lee, T. S.; Steen, E.; Keasling, J. D.; Trends Biotechnol 2008, 26, 375.

193. Wackett, L. P.; Cur. Opin. Chem. Biol. 2008, 12, 187.

194. Blanch, H. W; Adams, P. D.; Andrews-Cramer, K. M.; Frommer, W. B.; Simmons, B. A.; Keashing, J. D. S.; ACS Chem. Biol. 2008, 3, 17.

195. Kalscheuer, R.; Stoveken, T.; Luftmann, H.; Malkus, U.; Reichelt, R.; Steinbuchel, A.; Appl. Envir. Microbiol. 2006, 72, 1373.

196. Kalscheuer, R.; Stoling, T.; Steinbuchel, A.; Microbiology 2006, 152, 2529.

197. Antolin, G.; Tinaut, F. V.; Briceno, Y.; Castaño, V.; Perez, C.; Ramirez, A. I.; Bioresour. Technol. 2002, 83, 111.

198. Miao, X.; Wu, Q.; Bioresour. Technol. 2006, 97, 841.

199. Mohibbe Azam, M.; Waris, A.; Nahar, N. M.; Biomass and Bioenergy 2005, 29, 293.

200. Sarin, R.; Sahrma, M.; Sinharay, S.; Mallotra, R. K.; Fuel 2007, 86, 1365.

201. Tiwari, A. K.; Kumar, A.; Raheman, H.; Biomass Bioenergy 2007, 31, 569.

202. Wood, P.; Refocus 2005, July/August, 40.

203. Wu, W. H.; Food Chem. 2007, 104, 341.

204. Sampson, M.; Dodds, J.; Brown, J.; Lemus, R.; Stephens, J.; Workman, R.; Dabdoub, M. J.; Paiva, N.; Oklahoma Center of Advance on Science and Technology, Annual Meeting (Abstract), 2007.

205. Tyagi, P. D.; Kakkar, K. K.; Non-convencional vegetable oils, Batra book Service: New Delhi, 1991.

206. Knothe, G. J.; J. Am. Oil Chem. Soc. 2006, 83, 823.

207. Hilditch, T. P.; Willians, P. N.; The Chemical Constituints of Natural Fats, $4^{\text {th }}$ ed., Chapman and Hall: London, 1964.

208. Sheehan, J.; Dunahay, T.; Benemam, J.; Roessler, P.; A lookback at the U. S. Department of Energy's Aquatic Species Program-Biodiesel from Algal, Colorado, 1998.

209. Bertoldi, F. C.; Sant'Anna, E.; Braga, M. V. C.; Oliveira, J. L. B.; Grasas y aceites 2006, 57, 270.
210. Morais, M. G.; Costa, J. A. V.; Cienc. Agrotec. Lavras 2008, 32, 1245.

211. Tornabe, T. G.; Bourne, T. F.; Raziuddin, S.; Ben-Amotz, A.; Mar. Ecol. Prog. Ser. 1985, 22, 121.

212. Hu, Q.; Sommerfeld, M.; Jarvis, E.; Ghirardi, M.; Posewitz, M.; Seibert, M.; Darzins, A. L.; The Plant Journal 2008, 54, 621.

213. Van den Hoek, C.; Mann, D. G.; Jahns, H. M.; Algal: An Introduction to Phycology, Cambridge University Press: Cambridge, 1995.

214. Hu, Q.; Zhang, C. W.; Sommerfeld, M.; Annual Meeting of the Phycological Society of America, Alaska, 2006.

215. Basova, M. M.; Int. J. Algae 2005, 7, 33.

216. Cobelas, M. A.; Lechado, J. Z.; Grasas y aceites 1989, 40, 118.

217. Bigogno, C.; Khozin-Goldberg, I.; Boussiba, S.; Vonshak, A.; Cohen, Z.; Phytochemistry 2002, 60, 497.

218. De Swaff, M. E.; de Rijk, J. C.; Eggink, G.; Sijtsma, L.; J. Biotechnol. 1999, 70, 185.

219. Ohlrogge, J.; Browse, J.; The Plant Cell 1995, 7, 957.

220. Borowiztka, M. Em Microalgal Biotechnology; Borowitzka, M. A.; Borowitzka, L. J., eds.; Cambridge University Press: Cambridge, p. 257-287.

221. Xu, H.; Miao, X.; Wu, Q.; J. Biotechnol. 2006, 126, 499.

222. Dabdoub, M. J.; Rampin, M. A.; Le Blanc, G.; resultados não publicados.

223. Audi, J.; Belson, M.; Patel, M.; Shier, J.; Osterloh, J.; JAMA 2005, 294 , 2342.

224. Weiss, E. A.; Castor oilseed Crop, Blackwell Science: Oxford, 2000, p. 13-52.

225. Thorpe, S. C.; Kemeny, D. M. Panzani, R. C.; Mcguri, B.; Lord, M.; J. Allergy Clin. Immunol. 1988, 82, 67.

226. Sujatha, M.; Reddy, T. P.; Mahasi, M. J.; Biotechnol. Adv. 2008, 26, 424.

227. Tewari, D. N.; Jatropha and Biodiesel, Oceans Books Pvt Ltd: New Delhi, 2007, p. 1-28.

228. Ferrari, R.; Oliveira, V. S.; Scabio, A.; Sci. Agric. 2005, 62, 291.

229. Plank, C.; Lorbeer, E.; J. High Resolut. Chromatogr. 1993, 16, 483.

230. Pinto, A. C.; Guarieiro, L. L. N.; Rezende, M. J. C.; Ribeiro, N. M.; Torres, E. A.; Lopes, W. A.; Pereira, P. A. P.; de Andrade, J. B.; J. Braz. Chem. Soc. 2005, 16, 1313.

231. Conceição, M. M.; Candeia, R. A.; Silva, F. C.; Bezerra, A. F.; Fernandez, Jr., V. J.; Souza, A. G.; Renew and Sustainable Energy Reviews 2007, 11, 964 .

232. Baldwin, B. S.; Cossar, R. D.; Ind. Crops Prod. (2008), doi: 10.1016/j. indcrop.2008.06.004.

233. Mahanta, N.; Gupta, A.; Khare, S. K.; Bioresour. Technol. 2008, 99, 1729.

234. Rakshit, K. D.; Darukesshwara, J.; Rathina Raj, K.; Narasimhamuthy, K.; Saibaba, P.; Bhagya, S.; Food and Chemical Toxicology 2008, 46, 3621.

235. Godoy, M. G.; Gutarra, M. L. E.; Maciel, F. M.; Felix, S. P.; Enzyme Microb Technol (2009), doi:10.1016/j.enzmictec.2009.01.002. 